3

\title{
Insight into adsorption mechanism of cationic dye onto biosorbents derived
}

\author{
from agricultural wastes
}

\author{
Hai Nguyen Tran ${ }^{\mathrm{a}, b^{*}}$, Sheng-Jie You ${ }^{\mathrm{a}}$, Tien Vinh Nguyen ${ }^{\mathrm{c}}$, and Huan-Ping Chao ${ }^{\mathrm{a}}{ }^{*}$ \\ aDepartment of Environmental Engineering, Chung Yuan Christian University, Chungli 320, \\ Taiwan \\ ${ }^{\mathrm{b}}$ Department of Civil Engineering, Chung Yuan Christian University, Chungli 320, Taiwan \\ ${ }^{c}$ Faculty of Engineering and IT, University of Technology, Sydney (UTS), PO Box 123, Broadway, \\ Sydney, Australia
}

\begin{abstract}
This study investigated the phenomenon and mechanism of adsorption of methylene green 5 (MG5) on three pristine biosorbents: golden shower pod (GS), coconut shell (CC), and orange peel (OP). The results showed that the biosorbents possessed low specific surface areas, but abundant functional groups. Adsorption was strongly affected by the solution's $\mathrm{pH}$ and ionic strength. As revealed in the kinetic study, equilibrium was rapidly established, requiring low activation energies; a removal rate of $30 \%-87 \%$ was achieved within $1 \mathrm{~min}$. The maximum Langmuir adsorption capacities at $30{ }^{\circ} \mathrm{C}$ exhibited the following order: GS $(106 \mathrm{mg} / \mathrm{g})>\mathrm{OP}(92 \mathrm{mg} / \mathrm{g})>\mathrm{CC}(59 \mathrm{mg} / \mathrm{g})$. Thermodynamic experiments suggested that the adsorption occurred spontaneously $\left(-\Delta G^{\circ}\right)$ and exothermically $\left(-\Delta H^{\circ}\right)$. The primary adsorption mechanisms involved electrostatic attraction, hydrogen bonding formations, and $n-\pi$ interaction. Thermogravimetric analysis revealed that three biopolymer components (i.e., hemicellulose, cellulose, and lignin) played controlling roles in the adsorption process. Thus, these three agricultural residues can be considered potential low-cost adsorbents for efficient dye adsorption applications.
\end{abstract}

Keywords: Biosorbent; cationic dye; adsorption mechanism; biopolymer; agricultural waste

${ }^{*}$ Corresponding authors:

H.-N. Tran (trannguyenhai2512@ gmail.com), S.-J. You (sjyou@cycu.edu.tw), and H.-P. Chao (hpchao@cycu.edu.tw) 


\section{Introduction}

The presence of dyes and pigments in water bodies is enormously concerning for public

health. A variety of synthetic dyes are used in many industries, including leather, textile, paper,

37 rubber, dyestuff, cosmetics, plastics, pharmaceutical, printing, food, paint, pigment, petroleum,

pesticide and wood-preserving chemical industries. Notably, over 100,000 known commercial

dyes exist, and of the approximately 700,000 tons of dye produced each year, 10,000 tons are subsequently discharged into wastewater streams (Raval et al., 2016). The uncontrolled and untreated discharge of abundant colored wastewater into the water environment has attracted

42 substantial attention because dyes' toxic, carcinogenic, mutagenic, and allergenic properties adversely affect aquatic organisms and human health.

Adsorption technology is considered the most economically favorable technique to remove dyes among those available (i.e., membrane separation, oxidation, and irradiation) because of its high removal efficiency, low operation cost, and ability to separate a wide range of contaminants from industrial effluents. Various biosorbents derived from agricultural and industrial wastes have been efficiently applied to remove different types of dyes in the literature, such as acid, cationic, dispersive, direct, reactive, solvent, sulfur, and vat dyes (Annadurai et al., 2002; Gupta and Suhas, 2009; Contreras et al., 2012; Witek-Krowiak, 2013; Wang et al., 2014; Oladipo and Gazi, 2015;

Roosta et al., 2015; Sadaf et al., 2015; Jeyagowri and Yamuna, 2016; Tahir et al., 2017). Although the removal efficiencies of biosorbents are lower than that of activated carbon, the industrial-scale utilization of these materials is economically attractive (Contreras et al., 2012).

Natural lignocellulosic biomasses from agricultural residues can be regarded as low-cost and renewable materials for the decolorization of wastewater effluents from the textile industry 56 because of the presence of biopolymers, such as polysaccharides, lignin, hemicelluloses, and 
57 cellulose. These biopolymers include abundant oxygen-containing functional groups and are

58 potentially useful for the uptake of various contaminants from aqueous solutions. Methylene green

595 (MG5) is a cationic phenothiazine dye and heterocyclic aromatic chemical compound that can

60 be considered as a nitro derivative of methylene blue. In addition, MG5-commonly used in

61 various industries - shows considerable solubility in both polar organic media and water. However,

62 the factors contributing to the adsorption of MG5 on agricultural residues-derived biopolymers

63 have not been reported previously. In addition, the adsorption mechanisms of MG5 have not been

64 thoroughly described in the literature. Knowledge of these adsorption mechanisms is criterial for

65 determining the amounts of MG5 adsorbed on different biosorbents.

In this study, three biosorbents (i.e., golden shower pod [GS], coconut shell [CS], and

67 orange peel $[\mathrm{OP}]$ ) were used to investigate the uptake process of MG5 from an aqueous solution.

68 The biosorbents were selected based on their popularity and different properties, especially the

69 difference about the quantity of their biopolymer components (i.e., hemicellulose, cellulose, and

70 lignin). The batch adsorption experiments were performed under different operation conditions

71 (i.e., solution $\mathrm{pH}$, ionic strength, contact time, initial concentration, temperature, and desorption

72 agent) to determine their effects on the adsorption process. The important contributions of the

73 tested biopolymers toward the total adsorption of MG5 were examined thoroughly by conducting

74 detailed comparisons of the changes in the biosorbents' properties after adsorption using various

75 techniques (i.e., thermogravimetric analysis [TGA], Fourier transform infrared [FT-IR]

76 spectroscopy, and Boehm titration).

77 


\section{Materials and methods}

\subsection{Biosorbent preparation}

The GS, CC, and OP were obtained from a local market in Taiwan. The collected samples were first washed with tap water at least three times and then with deionized distilled water to remove water-soluble impurities and surface-adhered particles. Then, they were placed in an oven at $105^{\circ} \mathrm{C}$ for $48 \mathrm{~h}$ to remove excess water and moisture. The dried samples were ground and sieved to obtain the desired particle sizes $(0.106-0.250 \mathrm{~mm})$. The samples were stored in tightly closed brown glass bottles and used as potential biosorbents without any further treatment.

\subsection{Biosorbent analysis}

The biosorbent samples were degassed at $110{ }^{\circ} \mathrm{C}$ for $24 \mathrm{~h}$ in a vacuum oven before the measurements. The textural properties were measured by collecting nitrogen adsorptiondesorption isotherms (Micromeritics ASAP 2020 sorptometer) at $77 \mathrm{~K}$. The morphology of the adsorbents was determined using scanning electron microscopy (SEM; Hitachi S-4800, Japan) with an accelerating voltage of $3 \mathrm{kV}$. Before observation, the samples were coated with gold in E1010 Ion sputter. The thermal stability was measured by TGA (DuPont TA Q50, USA) under an air atmosphere. The experiment was conducted from room temperature to $900{ }^{\circ} \mathrm{C}$ with a heating rate of $10{ }^{\circ} \mathrm{C} / \mathrm{min}$. Proximate analysis was performed by following an international standard procedure (ASTM).

The superficial chemistry of the biosorbent was elucidated using three techniques. Firstly, the functional groups present on the adsorbent surface were detected using FT-IR (FT/IR-6600 JASCO). The spectra were scanned from 4,000 to $650 \mathrm{~cm}^{-1}$. Secondly, the $\mathrm{pH}$ values of the biosorbents at the point of zero charge $\left(\mathrm{pH}_{\mathrm{PZC}}\right)$ were determined using "the drift method". Recently, Tran and coworkers (2017b) investigated the effects of operation conditions on the pHpzC of 
101 commercial activated-charcoal using "the drift method". The results demonstrated that the point 102 of zero charge $(9.81 \pm 0.07)$ of charcoal was insignificantly dependent on the operation conditions 103 (i.e., $\mathrm{CO}_{2}$, solid/liquid ratio, electrolyte type, electrolyte concentration, and contact time). Thirdly, 104 the quantities of acidic groups and basic sites on the adsorbent surface were determined through 105 Boehm titration, following the standardized protocol proposed by Goertzen and coworkers (2010).

106 The numbers of moles of adsorbent surface functionalities were determined from the equations 107 reported in our recent publication (Tran et al., 2017e).

\subsection{Dye adsorption study}

\subsubsection{Batch adsorption experiment}

All of the MG5 solutions were serially diluted from an MG5 stock solution (1,000 mg/L).

112 The stock solution was prepared by dissolving a given amount of MG5 in deionized distilled water. 113 All chemicals used in this study were of analytical grade.

The effect of the $\mathrm{pH}$ on the dye adsorption capacity was measured by mixing $25-\mathrm{mL}$ solutions containing 300-mg/L MG5 with $0.1 \mathrm{~g}$ of each biosorbent using solutions with various $\mathrm{pH}$ values. The initial $\mathrm{pH}$ value was adjusted from 2.0 to $10.0 \pm 0.2$ by adding $1-\mathrm{M} \mathrm{NaOH}$ or $1-\mathrm{M}$

$117 \mathrm{HCl}$. Similarly, the influence of the ionic strength was examined by varying the $\mathrm{NaCl}$ 118 concentration from 0 to $0.5 \mathrm{M}$. The kinetic adsorption study was conducted using a series of 100$\mathrm{mL}$ Erlenmeyer flasks containing $50 \mathrm{~mL}$ of MG5 solution at $30{ }^{\circ} \mathrm{C}$ and $50{ }^{\circ} \mathrm{C}$. Adsorption isotherms were collected using MG5 concentrations ranging from approximately 100 to 1,000

$121 \mathrm{mg} / \mathrm{L}$ at different temperatures. The thermodynamic parameters were estimated at three different 122 temperatures for various MG5 concentrations (approximately 100-1,000 mg/L). The MG5123 biosorbent mixtures were shaken using an orbital-shaking incubator (S300R-Firstek) at $150 \mathrm{rpm}$. 
124 After predetermined intervals, the mixtures were separated using glass fiber filters. The MG5-

125 laden biosorbent was rinsed with deionized distilled water, dried, and stored for further 126 experiments (i.e., FT-IR, TGA, and desorption). The MG5 concentration in solution was

127 determined using ultraviolet-visible spectrophotometry (Genesys 10 UV-Vis; Thermo Scientific)

128 at the wavelengths of maximum absorption (Fig. 1). The amount of MG5 uptake at equilibrium,

$129 q_{e}(\mathrm{mg} / \mathrm{g})$, was calculated by the mass-balance equation.

$$
q_{e}=\frac{\left(C_{o}-C_{e}\right)}{m_{1}} V_{1}
$$

137 relationship:

$$
q_{r}=q_{e}-q_{d}=q_{e}-\frac{C_{d}}{m_{2}} V_{2}
$$

138 where $q_{r}(\mathrm{mg} / \mathrm{g})$ is the mass of MG5 that remained adsorbed at the end of the desorption study, $C_{d}$ $139(\mathrm{mg} / \mathrm{L})$ is the concentration of MG5 in the solution after desorption, and $q_{d}(\mathrm{mg} / \mathrm{g})$ is the mass of 140 MG5 desorbed if the adsorption was reversible.

\subsubsection{Statistical analysis}

\section{Figure 1}

The adsorption reversibility was determined by desorption experiments. A given mass of MG5-loaded biosorbent $\left(m_{2}\right)$ was desorbed using $0.025 \mathrm{~L}$ of various desorbing agents $\left(V_{2}\right)$. The amount of MG5 remaining on the biosorbent was estimated by the following mass-balance 
144 add-in (Microsoft Excel) to compute the parameters of the isotherm and kinetic models. The 145 coefficient of determination $\left(R^{2}\right)$ of the non-linear optimization method was computed using Eq.

146 3. To identify the best-fit model for the adsorption process, the chi-square $\left(\chi^{2}\right)$ and non-linear $R^{2}$ 147 values were determined (Tran, You et al. 2016a, Tran, You et al. 2017f, Tran, You et al. 2017d). 148

$$
\begin{aligned}
& R^{2}=1-\frac{\sum\left(q_{\mathrm{e}, \mathrm{xxp}}-q_{e, c a l}\right)^{2}}{\sum\left(q_{\mathrm{e}, \mathrm{exp}}-q_{e, \text { mean }}\right)^{2}}=\frac{\sum\left(q_{e, c a l}-\mathrm{q}_{\mathrm{e}, \mathrm{mean}}\right)^{2}}{\sum\left(q_{e, c a l}-\mathrm{q}_{\mathrm{e}, \text { mean }}\right)^{2}+\sum\left(q_{e, c a l}-\mathrm{q}_{\mathrm{e}, \mathrm{exp}}\right)^{2}} \\
& \chi^{2}=\sum \frac{\left(q_{e, \text { exp }}-q_{e, c a l}\right)^{2}}{q_{e, c a l}}
\end{aligned}
$$

149 where $q_{e, \exp }(\mathrm{mg} / \mathrm{g})$ is the MG5 uptake at equilibrium obtained from Eq. $1, q_{e, c a l}(\mathrm{mg} / \mathrm{g})$ is the MG5 150 uptake determined from the model after using the Solver add-in, and $q_{e, \text { mean }}(\mathrm{mg} / \mathrm{g})$ is the mean 151 value of $q_{e, \text { exp. }}$

\section{Results and discussion}

\subsection{Biosorbent characteristics}

The basic properties of the biosorbents are listed in Table 1. Clearly, the biosorbents have 155 low specific surface areas and total pore volumes, in agreement with their rough and heterogeneous 156 morphologies shown in Figure 2. In addition, the biosorbents possess non-uniform sizes and shapes 157 (Figure 2).

\section{Table 1}

\section{Figure 2}

Figure 3 and Table 2 present qualitative information on the functional groups (chemical 161 bonds) available on the surfaces of the biosorbents and their spectroscopic assignments, 162 respectively. The spectra of the three biomass samples are typical of lignocellulose material. The 
163 intense bands at approximately $3400 \mathrm{~cm}^{-1}$ are assigned to the $(-\mathrm{OH})$ stretching vibrations of the

164 hydroxyl groups in hemicellulose, cellulose, and lignin. The moderate peaks observed at roughly $1652920 \mathrm{~cm}^{-1}$ are attributed to either asymmetric or symmetric $\mathrm{C}-\mathrm{H}$ stretching vibrations of the 166 methyl $\left(-\mathrm{CH}_{3}-\right)$ and methylene $\left(-\mathrm{CH}_{2}-\right)$ groups, as expected for hemicellulose, cellulose, and 167 lignin (Köseoğlu and Akmil-Başar, 2015). The presence of a carbon-carbon triple bond $(\mathrm{C} \equiv \mathrm{C})$ in 168 disubstituted alkynes is indicated by the peaks at approximately $2350 \mathrm{~cm}^{-1}$. The presence of 169 carboxylic and lactonic groups $(\mathrm{C}=\mathrm{O})$ is evidenced by the well-defined bands at roughly $1470 \mathrm{~cm}^{-}$

170 . Similarly, the recognized bands at approximately $1620 \mathrm{~cm}^{-1}$ are ascribed to $\mathrm{C}=\mathrm{C}$ double bonds 171 in aromatic rings. The IR peaks near $1250 \mathrm{~cm}^{-1}$ are attributable to the $\mathrm{C}-\mathrm{O}-\mathrm{C}$ stretching of aryl172 alkyl ether linkages in lignin (Yang et al., 2007). Notably, the characteristic peak of $\mathrm{C}-\mathrm{O}-\mathrm{C}$ in the 173 spectrum of OP exhibited a very low intensity, indicating that the OP might contain less lignin 174 compounds than the woody samples (i.e., GS and CC). Finally, the $\mathrm{C}-\mathrm{O}$ stretching vibrations of 175 cellulose structure are responsible for the sharp bands at approximately $1050 \mathrm{~cm}^{-1}$ (Mujtaba et al., 176 2016; Tran, You et al. 2017f).

Figure 3

\section{Table 2}

The pyrolytic characteristics of the examined biomass were determined using a 181 thermogravimetric analyzer, and they are presented in Figure 4 and Table 3. For the MG5-unloaded 182 biosorbent, four overlapping peaks corresponding to the maximum weight loss values are observed 183 in the thermogravimetric curves, except for that of OP. The weight loss temperatures $\left(T_{\max }\right)$ were 184 lower than $85^{\circ} \mathrm{C}$ because of the vaporization of moisture, and the thermal decomposition peaks at $185 T_{\max }$ values of $237-299{ }^{\circ} \mathrm{C}, 327-341{ }^{\circ} \mathrm{C}$, and $498-700{ }^{\circ} \mathrm{C}$ were attributed to the thermal 
186 degradation of hemicellulose, cellulose, and lignin, respectively. These results are consistent with 187 those of Yang and colleagues (2007). They noted that the pyrolysis of pure hemicellulose and 188 cellulose occurred at $220-315^{\circ} \mathrm{C}\left(T_{\max }=268^{\circ} \mathrm{C}\right)$ and $315-400{ }^{\circ} \mathrm{C}\left(T_{\max }=335^{\circ} \mathrm{C}\right)$, whereas pure 189 lignin was more difficult to decompose $\left(160-900{ }^{\circ} \mathrm{C}\right)$. The weight loss values of the three main 190 components of the tested biomasses exhibited the following order: lignin $(37.9 \%)>$ cellulose $191(30.1 \%)>$ hemicellulose $(26.8 \%)$ for GS; lignin $(33.2 \%)>$ hemicellulose $(28.7 \%)>$ cellulose $192(23.5 \%)>$ for CC; and cellulose $(32.4 \%)>$ lignin $(27.9 \%)>$ hemicellulose $(19.5 \%)$ for OP. The 193 onset and endset values of the biosorbents, which were extrapolated based on the intersection of 194 two tangent lines of the TGA curves, provide additional useful information regarding the thermal 195 stability of these biomasses. The onset and endset of $\mathrm{CC}\left(244\right.$ and $\left.641^{\circ} \mathrm{C}\right)$ were higher than those 196 of GS $\left(244\right.$ and $\left.605{ }^{\circ} \mathrm{C}\right)$ and OP $\left(188\right.$ and $\left.337^{\circ} \mathrm{C}\right)$, respectively, indicating that GS is more 197 thermally stable than the other tested biosorbents.

\section{Figure 4}

\section{Table 3}

\subsection{Effects of pH and ionic strength}

201

The surface charges of the biosorbents in solution were characterized by the point of zero

202 charge (PZC). The PZC was defined as the $\mathrm{pH}$ value at which the net (external and internal) surface 203 charges on an adsorbent are zero. Essentially, when the $\mathrm{pH}$ of a solution $\left(\mathrm{pH}_{\text {solution }}\right)$ exceeds the 204 pHPZC, the adsorbent's surface becomes negatively charged because of the deprotonation of 205 oxygen-containing surface groups (i.e., $-\mathrm{COOH}$ and $-\mathrm{OH}$ ), favoring the adsorption of cationic 206 ions from the solution and vice versa. The $\mathrm{pH}$ PZC values of the biosorbents were as follows: CC $207(\mathrm{pH} P \mathrm{PZC}=6.5)>\mathrm{OP}(5.3)>\mathrm{GS}(3.8)$. Thus, the acidic oxygen-containing functional groups 
exhibited the following order: GS $(8.74 \mathrm{mmol} / \mathrm{g})>\mathrm{OP}(6.90 \mathrm{mmol} / \mathrm{g})>\mathrm{CC}(4.21 \mathrm{mmol} / \mathrm{g})$ (Figure 5a and Table 1).

The $\mathrm{pH}$ dependence of MG5 adsorption is presented in Figure 5b. Clearly, the adsorption of MG5 by the biosorbent occurred when $\mathrm{pH}_{\text {solution }}<\mathrm{pH}$ PZC. Indeed, at a low $\mathrm{pH}(2.0)$, the biosorbents were still able to adsorb MG5 molecules, although at this $\mathrm{pH}$, the excess $\mathrm{H}^{+}$ions present in the system showed strong competition with the cationic MG5 molecules for the active adsorption sites. Notably, this was not observed for CC. This result might indicate that mechanisms other than electrostatic attraction (i.e., hydrogen bonding or $n-\pi$ interactions) exist. The dyeremoval capacity is highly dependent on the $\mathrm{pH}$ PZC of the biosorbent. The amount of dye adsorbed increased substantially as the solution $\mathrm{pH}$ increased and plateaued when $\mathrm{pH}_{\text {solution }}>\mathrm{pH}$ PZC (Figure 5b). An analogous result was found in the literature (Ncibi et al., 2009).

Figure 5c shows the influence of the ionic strength on the MG5 uptake. Clearly, the adsorption capacities of the biosorbents were inhibited by the presence of univalent electrolyte in the solution. The magnitude of the effect of the $\mathrm{NaCl}$ concentration on $q_{e}(\mathrm{mg} / \mathrm{g})$ varies widely between adsorbents. For example, $0.05 \mathrm{M}_{\text {of }} \mathrm{Na}^{+}$ions is sufficient to compete with MG5 ions for the binding sites on the surfaces of GS and CC, whereas for OP, a concentration of $0.1 \mathrm{M}$ is needed. Therefore, the following conclusions can be drawn: (1) a screening effect (known as electrostatic screening) exists between the positively charged biosorbent surface and MG5 molecules, and (2) the electrostatic force plays a vital role in the adsorption mechanism.

\section{Figure 5}

\subsection{Adsorption kinetics}

The effect of the contact time on the uptake amount of MG5 at different temperatures is described in Figure 6. The dye-removal rate increased continuously during the initial 10 min of 
231 contact; subsequently, the removal rate decreased slightly and plateaued after approximately 30

$232 \mathrm{~min}$ for OP, $60 \mathrm{~min}$ for $\mathrm{CC}$, and $120 \mathrm{~min}$ for GS. In addition, the amount of dye removed decreased

233 at higher temperatures, suggesting that the adsorption process is favored at lower temperatures.

234 The instantaneous adsorption phenomenon indicated that the biosorbents have strong affinities for

235 the cationic dye molecules. The kinetics plays a significant role, facilitating scaling the process up

236 to small reactor volumes to ensure efficiency and economy.

\section{Figure 6}

In this study, several kinetic models were applied to mathematically describe the intrinsic 239 adsorption constants. The non-linearized forms of the pseudo-first-order (Lagergren, 1898) and 240 pseudo-second-order (Blanchard et al., 1984) models are expressed in Eqs. 5-6. The Elovich 241 model (Roginsky and Zeldovich, 1934) and intra-particle model (Weber and Morris, 1963) are 242 presented in Eqs 7-8, respectively.

$$
\begin{aligned}
& q_{t}=q_{e}\left(1-e^{-k_{1} t}\right) \\
& q_{t}=\frac{q_{e}^{2} k_{2} t}{1+k_{2} q_{e} t} \\
& q_{t}=\frac{1}{\beta} \ln (1+\alpha \beta t) \\
& q_{t}=k_{i p} \sqrt{t}+C
\end{aligned}
$$

243 where $k_{1}(1 / \mathrm{min}), k_{2}(\mathrm{~g} / \mathrm{mg} \times \mathrm{min}), \alpha(\mathrm{mg} / \mathrm{g} \times \mathrm{min})$, and $k_{i p}(\mathrm{mg} / \mathrm{g} \times \mathrm{min})$ are the rate constants of the

244 pseudo-first-order, pseudo-second-order, Elovich, and intra-particle diffusion models, respectively; $245 q_{e}$ and $q_{t}$ are the amounts of MG5 uptake per mass of the biosorbent at equilibrium and any time $t$ 246 (min), respectively; $\beta(\mathrm{mg} / \mathrm{g})$ is the desorption constant during any one experiment; and $C(\mathrm{mg} / \mathrm{g})$ 
247 is a constant describing the thickness of the boundary layer. Higher values of C correspond to a 248 greater effect on the limiting boundary layer.

249 The activation energy of the sorption process $(E a ; \mathrm{kJ} / \mathrm{mol})$ can be predicted using the 250 Arrhenius equation. Eq. 10 describes the activation energy estimated based on adsorption kinetics 251 experiments performed at two temperatures:

$$
\begin{aligned}
& k=A e^{-E_{a} / R T} \\
& \ln k_{(323 K)}-\ln k_{(303 K)}=\left(\ln A-\frac{E_{a}}{R T_{2}}\right)-\left(\ln A-\frac{E_{a}}{R T_{1}}\right) \quad \Leftrightarrow \quad E_{a}=\frac{R \ln \frac{k_{(323 K)}}{k_{(303 K)}}}{\frac{1}{T_{1}}-\frac{1}{T_{2}}}
\end{aligned}
$$

252 where $k_{(323 K)}$ and $k_{(303 K)}$ are the rate constants of the kinetic model at $323 \mathrm{~K}$ and $303 \mathrm{~K}$, 253 respectively; $A$ is the pre-exponential factor (i.e., the frequency factor); $R$ is the universal gas 254 constant $(8.314 \mathrm{~kJ} / \mathrm{mol} \times \mathrm{K})$; and $T$ is the absolute temperature in Kelvin.

255 Table 4 lists the relative kinetic parameters for dye adsorption at two temperatures. 256 According to the coefficient of determination $\left(R^{2}\right)$, and chi-square $\left(\chi^{2}\right)$, it can be concluded that the 257 experimental data of adsorption kinetics were adequately described by the Elovich model $\left(R^{2}=\right.$ $258 \quad 0.955-0.994$ and $\left.\chi^{2}=0.089-8.681\right)$ than the others, such as the intra-particle diffusion model 259 (0.739-0.911 and 0.161-13.07), the pseudo-second-order model (0.475-0.963 and 1.514-9.165), 260 and the pseudo-first-order model (0.258-0.874 and 5.105-30.81), respectively. The better fit of 261 experimental data with the Elovich model suggested that the surfaces of biosorbent are a 262 heterogeneous system, which is in accordance with the observation of their morphology in Figure 2632. 
As demonstrated in Table 4, the adsorption rates (i.e., $k_{1}, k_{2}$, and $\alpha$ ) of the biosorbents

266

267

268

269

270

271

272

273

274

275

276

277

278

279

280

281

282

283

284

285

286

exhibited the following order: OP $>\mathrm{CC}>\mathrm{GS}$. This result is consistent with the order determined for the removal percentages of MG5 at $1 \mathrm{~min}$ and $5 \mathrm{~min}$ of contact: $87 \%$ and $93 \%(\mathrm{OP})>71 \%$ and $78 \%(\mathrm{CC})>30 \%$ and $52 \%(\mathrm{GS})$, respectively. Equilibrium was established rapidly because (1) the low activation energies ( $E a$ ) were required (Tran, You et al. 2017f), and (2) the adsorption process only occurred in two steps associated with transport processes (Figure 6). In addition, the negative values of $E a$ (from -62.23 to $-3.52 \mathrm{~kJ} / \mathrm{mol}$ ) reflected the exothermic nature of the adsorption process, and the low values of this parameter confirmed that physical adsorption occurred via relatively weak attraction forces.

Notably, the rates (i.e., $k_{1}, k_{2}$, and $\alpha$ ) of MG5 adsorption remarkably decreased with an increase in temperatures, confirming that the adsorption process occurred with a slower speed when the temperature of the solution increased.

\section{Table 4}

\subsection{Adsorption isotherms}

Although adsorption isotherms can contribute to elucidating adsorption mechanisms, it is less helpful in this regard than kinetics and thermodynamics. However, collecting adsorption isotherms is a useful strategy to both describe the relationship between the adsorbate concentration in the solution (liquid phase) and the adsorbent (solid phase) at a constant temperature and design adsorption systems. In this study, the Langmuir (Eq. 11), Freundlich (Eq. 12), and DubininRadushkevich (Eqs. 13-15) models were employed to describe both the adsorptive behavior of 
287 cationic dye on different biosorbents. To minimize the respective error functions, the non-linear

288 optimization technique was employed to calculate the adsorption parameters using these models.

$$
\begin{aligned}
& q_{e}=\frac{Q_{\max }^{0} K_{L} C_{e}}{1+K_{L} C_{e}} \\
& q_{e}=K_{F} C_{e}^{n} \\
& q_{e}=q_{D R} e^{-K_{D R} \varepsilon^{2}} \\
& \varepsilon=R T \ln \left(1+\frac{1}{C_{e}}\right) \\
& E=\frac{1}{\sqrt{2 K_{D R}}}
\end{aligned}
$$

289 where $q_{e}$ and $C_{e}$ are obtained from Eq. $1 ; Q^{o}{ }_{\max }(\mathrm{mg} / \mathrm{g})$ is the maximum saturated monolayer 290 adsorption capacity of the adsorbent; $K_{L}(\mathrm{~L} / \mathrm{mg})$ is the Langmuir constant related to the affinity 291 between the adsorbent and adsorbate; $K_{F}\left[(\mathrm{mg} / \mathrm{g}) /(\mathrm{mg} / \mathrm{L})^{\mathrm{n}}\right]$ is the Freundlich constant, which 292 characterizes the strength of adsorption; $n$ (dimensionless; $0<n<1$ ) is a Freundlich intensity 293 parameter that reflects the magnitude of the adsorption driving force or surface heterogeneity (the 294 adsorption isotherm becomes linear for $n=1$, favorable for $n<1$, and unfavorable for $n>1$; (Hai, 295 2017)); $q_{R D}(\mathrm{mg} / \mathrm{g})$ is the adsorption capacity; $K_{R D}\left(\mathrm{~mol}^{2} / \mathrm{kJ}^{2}\right)$ is a constant related to the sorption 296 energy; $\varepsilon$ is the Polanyi potential; and $E(\mathrm{~kJ} / \mathrm{mol})$ is the mean adsorption energy.

297 Hall and colleagues (1966) stated that the essential characteristics of the Langmuir 298 isotherm model can be expressed in terms of a dimensionless constant separation factor or 299 equilibrium parameter $R_{L}$, which is defined as follows:

$$
R_{L}=\frac{1}{1+K_{L} C_{o}}
$$


where $R_{L}$ is a constant separation factor (dimensionless), $K_{\mathrm{L}}$ is a Langmuir equilibrium constant,

301

302 $303\left(R_{L}=0\right)$.

304

305

306

307

308

309

310

311

312

313

314

315

316

317

318

and $C_{\mathrm{o}}$ is the initial MG5 concentration. The isotherm shape was used to predict whether the adsorption system was favorable $\left(0<R_{L}<1\right)$, unfavorable $\left(R_{L}>1\right)$, linear $\left(R_{L}=1\right)$, or irreversible

The MG5 adsorption isotherms for the biosorbents at different operation temperatures are presented in Figure 7. Clearly, the region in which the experimental data relating to the adsorption equilibrium are located is the Langmuir region, which is characterized by saturation at high concentrations. The higher determination coefficient $\left(R^{2}\right)$ and lower chi-square $\left(\chi^{2}\right)$ values of the Langmuir model relative to those of the Freundlich model supports this hypothesis (Table 5). Thus, the Langmuir model adequately described the equilibrium adsorption data.

According to the classification of adsorption isotherm shapes proposed by Giles and coworkers (1974), the isotherm shapes of GS and CC (Figure 7) were classified as H-type (high affinity); this type is characterized by extremely strong adsorption at low concentrations, followed by a pseudo-plateau. In contrast, the isotherm shape of OP could be classified as L-type (Langmuir); an initial concave region relative to the concentration axis characterizes this type. This result could support the assumption that the CC and GS samples would exhibit different adsorption mechanisms relative to the OP sample.

\section{Figure 7}

Table 5 lists the adsorption parameters obtained under the three temperatures tested. The maximum monolayer adsorption capacities for MG5 were ranked as follows: GS (106 mg/g) > OP $(92 \mathrm{mg} / \mathrm{g})>\mathrm{CC}(59 \mathrm{mg} / \mathrm{g})$. As shown in Figure 7, the adsorption efficiency is strongly affected by the operation temperature. The uptake amount of MG5 decreased as the temperature increased, 
323 indicating that the dye-adsorption process is exothermic. The decrease in the adsorption capacity

324 at higher temperatures is ascribed to the decrease of the adsorption energy Ea (Table 5).

325 Furthermore, the Ea values of the OP sample $(0.018-0.031 \mathrm{~kJ} / \mathrm{mol})$ were substantially lower than

326 those of GS $(0.18-0.87 \mathrm{~kJ} / \mathrm{mol})$ and $\mathrm{CC}(0.191-0.213 \mathrm{~kJ} / \mathrm{mol})$, demonstrating that GS and CC

327 might possess different adsorption mechanisms than OP.

328

329

330

331

332

333

334

$$
\Delta G^{o}=-R T \ln K_{C}
$$

$335 \Delta \mathrm{G}^{\mathrm{o}}, \Delta \mathrm{H}^{\mathrm{o}}$, and $\Delta \mathrm{S}^{\mathrm{o}}$ are related as follows:

$$
\Delta G^{o}=\Delta H^{0}-T \Delta S^{0}
$$

336 The well-known van't Hoff equation is obtained by substituting Eq. 17 into Eq. 18

$$
\ln K_{C}=\frac{-\Delta H^{o}}{R} \times \frac{1}{T}+\frac{\Delta S^{o}}{R}
$$

The Gibbs energy change $\left(\Delta G^{\mathrm{o}}\right)$ can be directly calculated from Eq. 17, whereas the enthalpy change $\left(\Delta H^{\circ}\right)$ and entropy change $\left(\Delta S^{\mathrm{o}}\right)$ were determined from the slope and intercept, respectively, of a plot of $\ln K_{\mathrm{C}}$ against $1 / \mathrm{T}$ (Eq. 19). The equilibrium constant $\left(K_{C}\right)$ must be 
341 calculate the thermodynamic parameters $\left(\Delta G^{\mathrm{o}}, \Delta H^{\mathrm{o}}\right.$, and $\left.\Delta S^{\mathrm{o}}\right)$. Thus, $K_{C}$ can be easily obtained as

342 a dimensionless parameter by multiplying $K_{L}$ by $10^{6}$ (the solution density, assuming that the 343 density of pure water is $1.0 \mathrm{~g} / \mathrm{mL}$ ) (Milonjić, 2009; Tran, You et al. 2016b; Tran, You et al. 2017d)

344 The thermodynamic parameters of the dye adsorption process are listed in Table 6. The 345 negative values of $\Delta G^{\circ}$ at all investigated temperatures suggest that the adsorption phenomenon 346 occurred favorably and spontaneously. This conclusion is in good agreement with the hypotheses 347 relating to the separation factor $\left(0<R_{L}<1\right)$ and Freundlich exponent $n$ described in Section 3.4. 348 Meanwhile, the negative $\Delta H^{\circ}$ reflects the exothermic nature of the adsorption process, which was 349 demonstrated by a decrease in the adsorption capacity (Figures 6-7) and the equilibrium constant 350 (Table 6) at higher temperatures. The $-\Delta H^{\circ}$ values also imply that energy is released as heat to the 351 surroundings via physisorption, chemisorption, or a mixture of both processes (comprehensive 352 adsorption). However, the low $\Delta H^{\circ}$ magnitudes (from -28.33 to $-4.15 \mathrm{~kJ} / \mathrm{mol}$ ) indicate that MG5 353 is removed via physisorption (Tran et al., 2016b). $\Delta S^{\circ}$ exhibits the opposite trend relative to those 354 of $-\Delta H^{\circ}$ and $\Delta G^{\circ}$ for the three biosorbents. The dye adsorption onto GS and $\mathrm{CC}$ is increasingly $355 \operatorname{random}\left(\Delta S^{\circ}>0\right)$, whereas that onto OP becomes less random $\left(\Delta S^{\circ}<0\right)$. This difference involves 356 the sign of the entropy change and may indicate that these materials exhibit different adsorption 357 mechanisms.

Table 6

\subsection{Adsorption reversibility} adsorption reversibility was investigated using various desorbing agents, such as deionized water 
364 ( $\mathrm{pH} 2.0), 0.1-\mathrm{M} \mathrm{HCl}$, methanol, and 0.1-M NaCl. If the dye adsorbed onto the adsorbents surface

365 is easily desorbed by $\mathrm{NaCl}$ or $\mathrm{HCl}$, the adsorption mechanism must involve electrostatic attraction

366 between the negatively changed groups (i.e., $-\mathrm{COO}^{-}$) on the surface of the biosorbent and the

367 cationic MG5 molecules. In contrast, the desorption of dye by methanol might correspond to other

368 types of interactions (i.e., hydrogen bonding or $n-\pi$ interactions). Based on Figure 8 , which

369 presents the percentage values of MG5 desorption, the primary mechanisms for MG5 adsorption

370 are electrostatic interactions ( $>16 \%$ for GS, $28 \%$ for CC, and $>60 \%$ for OP) and other interactions

371 involving the oxygen-containing functional groups on the biosorbent surface (approximately $76 \%$

372 for GS, $62 \%$ for $\mathrm{CC}$, and $34 \%$ for OP). Cation exchange could play a minor role in the adsorption

373 of the dye onto the adsorbents (below 10\%). Based on the isotherm shapes and the results of the

374 kinetic study, the effects of the $\mathrm{pH}$ and ionic strength, the adsorption energy, thermodynamics, and 375 the desorption study, GS and CC likely have similar adsorption mechanisms.

Figure 8

\section{$377 \quad 3.7$. Possible adsorption mechanisms}

Generally, the possible mechanisms of cationic dye adsorption onto biosorbents are as

379 follows: (1) electrostatic attraction, (2) hydrogen bonding, and (3) $n-\pi$ interactions (Tran et al., 380 2017f). Notably, the specific surface areas of the analyzed biosorbents exhibited the following 381 order: GS $\left(5.72 \mathrm{~m}^{2} / \mathrm{g}\right)>\mathrm{CC}\left(3.16 \mathrm{~m}^{2} / \mathrm{g}\right)>\mathrm{OP}\left(2.08 \mathrm{~m}^{2} / \mathrm{g}\right)$; in contrast, the maximum adsorption 382 capacities were as follows: GS $(106 \mathrm{mg} / \mathrm{g})>\mathrm{OP}(92 \mathrm{mg} / \mathrm{g})>\mathrm{CC}(59 \mathrm{mg} / \mathrm{g})$. Therefore, the specific 383 surface area is relatively less important for the adsorption capacities of these three biosorbents.

384 Weak electrostatic attractions can occur between the negatively charged sites on the surface 385 of OP and the cationic MG5 molecules in the solution. Clearly, when $\mathrm{pH}_{\text {solution }}>\mathrm{pH}$ PZC, the 386 oxygen-containing functional groups (i.e., carboxylic and phenolic groups) become ionized, and 
387 thus, the $\mathrm{pH}$ of the solution decreases after adsorption (Figure $5 \mathrm{~d}$ ). The $\mathrm{pKa}$ values of the 388 carboxylic (2.0-4.0) and phenolic (8.0-9.0) groups also play a role in explaining the biosorbents' 389 surface charges. Both the carboxylic and phenolic groups can undergo dissociation, and can 390 become predominantly negatively charged when the solution $\mathrm{pH}$ exceeds their $\mathrm{pKa}$ values. The $391 \mathrm{pH}$ of the solution used in this study was nearly 7.0, and at this $\mathrm{pH}$ value, the $(-\mathrm{COOH})$ carboxylic 392 groups dissociate, forming negatively charged carboxylate $\left(-\mathrm{COO}^{-}\right)$groups. Thus, the carboxylic 393 groups directly account for the binding of MG5 onto the biosorbent surface (Figure 9a). This 394 finding is in agreement with the observed effects of the $\mathrm{pH}$ and ionic strength and the $\mathrm{pH}$ values 395 after adsorption and desorption.

Hydrogen bonding interactions can occur (1) between the surface hydrogens of the 397 hydroxyl groups (H-donors) on the adsorbent's surface and the appropriate atoms (i.e., nitrogen 398 and oxygen; H-acceptors) of MG5 (this phenomenon is also known as dipole-dipole hydrogen 399 bonding; Figure 9b) and (2) between the hydroxyl groups on the AC's surface and the aromatic 400 rings of MG5 (this phenomenon is also known as Yoshida hydrogen bonding; Figure 9c). The FT401 IR results demonstrated that the $-\mathrm{OH}$ groups at approximately $3400 \mathrm{~cm}^{-1}$ dramatically decreased 402 in intensity (Figure 3) and shifted toward slightly higher wavenumbers (Table 2), confirming the 403 existence of both dipole-dipole and Yoshida hydrogen bonding interactions (Blackburn, 2004). 404 However, OP exhibited the opposite behavior, showing an insignificant decrease in the intensity 405 of the peak at $3400 \mathrm{~cm}^{-1}$. Therefore, the hydrogen bonding interactions contribute little to the 406 adsorption mechanisms of OP. $\mathrm{n}-\pi$ interactions (or $\mathrm{n}-\pi$ electron donor-acceptor interactions) were originally proposed by 408 Mattson and colleagues (1969). In these interactions, the carbonyl oxygens on the surface of the 409 adsorbent act as electron donors, and the aromatic rings of MG5 act as electron acceptors (Figure 
410 9d). The FT-IR spectra revealed that the $\mathrm{C}=\mathrm{O}$ and $\mathrm{C}-\mathrm{O}$ peaks shifted and decreased in intensity

411 after MG5 adsorption (Figure 3 and Table 2). The shifts of the $\mathrm{C}=\mathrm{O}$ and $\mathrm{C}-\mathrm{O}$ peaks after the

412 adsorption of this aromatic species is consistent with previously reported results (Xing et al., 1994;

413 Tran et al., 2017f; Tran et al., 2017g). As found for hydrogen bonding, $\mathrm{n}-\pi$ interactions did not

414 constitute a major mechanism for adsorption on OP, as evidenced by the slight decreases in the

415 intensities of the $\mathrm{C}=\mathrm{O}$ and $\mathrm{C}-\mathrm{O}$ peaks.

416 The changes in the TGA curves before and after MG5 adsorption provide additional

417 information about the adsorption mechanisms. The onset and endset points of the three biosorbents

418 shift toward higher values (Figure 4 and Table 3), confirming the successful adsorption of MG5

419 on the biosorbent surface. Moreover, derivative thermogravimetric analysis (DTG) data revealed

420 that the magnitudes of the three components (i.e., hemicellulose, cellulose, and lignin) decreased

421 remarkably after adsorption. Thus, these three components contribute to dye adsorption. However,

422 the extent of their contributions may depend strongly on their amounts.

423 Assuming that the percentages of the dye desorbed by (1) $\mathrm{HCl}$ and $\mathrm{NaCl}$ reflected the

424 electrostatic attraction and (2) methanol indicated the interactions of oxygen-containing functional

425 groups, the contributions of these different adsorption mechanisms for the three adsorbents could

426 be described as follows: hydrogen bonding and $n-\pi$ interactions (76\% and $62 \%)$ and electrostatic

427 attraction (17\% and 28\%) for GS and CC, respectively; and electrostatic attraction (74\%) and 428 hydrogen bonding and $n-\pi$ interactions (34\%) for OP.

429 To identify the functional groups responsible for the adsorption, the dependence of the 430 MG5-adsorption capacity on the surface chemistry of the biosorbents were determined by 431 analyzing a plot of the $Q^{o}{ }_{\max }$ from the Langmuir model (Table 5) versus the functional groups 432 (Table 1). The results indicated that, based on the extremely high linear regression coefficient $\left(R^{2}\right.$ 
$433=0.996$ ), the acidic groups were involved in the dye-adsorption process, unlike the basic groups

$434\left(R^{2}=0.566\right)$. Among the acidic groups, the carboxylic groups played a more important role in the

435 adsorption of MG5 $\left(R^{2}=0.9803\right)$ compared to the phenolic $\left(R^{2}=0.6116\right)$ and lactonic $\left(R^{2}=0.4091\right)$

436 groups. Our recent study (Tran et al., 2017g) also demonstrated that the concentrations of total

437 acid groups (i.e., carboxylic and phenolic) on the hydrochar's surface determined the selective

438 adsorption order of the adsorbents: $\mathrm{GSH}>\mathrm{CCH}>\mathrm{OPH}$.

439 The interactions responsible for the adsorption of MG5 molecules by the tested biosorbents

440 are summarized in Figure 9.

\section{Figure 9}

\section{$442 \quad 3.8$. Comparison}

Because few studies have measured the removal of MG5 from solution by biosorbents,

444 Table 7 compares the $Q^{o}$ max values determined in this study with previously reported $Q^{o}$ max values

445 for various cationic dyes using different types of biosorbents. Clearly, the selective trend of the 446 maximum adsorption capacity is inversely proportional to the molecular weight $\left(M_{w}\right)$ of the dye.

447 According to Table 7, GS, CC, and OP are attractive alternatives for the removal of cationic dyes 448 from aqueous solutions.

\section{Table 7}

Furthermore, we also compared the $S_{\mathrm{BET}}$ and $Q^{o}{ }_{\max }$ of MG5 adsorption onto the biosorbents

451 in this study with those of the other adsorbents in the previous literature (Table 8). Theses

452 adsorbents comprised hydrochar (Tran et al., 2017g), biochar (Tran et al., 2017c), non-spherical

453 activated carbon (Shiau and Pan, 2005; Tran et al., 2017b; Tran et al., 2017f), spherical activated

454 carbon (Huang et al., 2014; Tran et al., 2017a), silver nanoparticles-loaded activated carbon (Ag-

455 NP-AC) and zinc oxide nanorods-loaded activated carbon (ZnONR-AC) (Ghaedi et al., 2014), 
mesoporous zeolite (MCM-41) (Lee et al., 2007), glucose hydrochar modified with $1 \%$

457 triethylenetetramine $\left(\mathrm{GH}-\mathrm{TETA}_{1} \%\right)$ and activated carbon modified with $1 \%$ triethylenetetramine

458 (GAC1\%) (Tran et al., 2017a), montmorillonite and activated clay (Shiau and Pan, 2005), titania

459 nanotube (Lin et al., 2010). The difference on the $Q^{o}$ max values between these adsorbents might

460 result from different primary adsorption mechanisms. For example, the MG5 adsorption

461 mechanisms for adsorption onto biosorbent and hydrochar were mainly regarded as electrostatic

462 attraction, while these for biochar and activated carbon were $\pi-\pi$ interaction and pore filling.

463 Furthermore, the differences in the adsorbent's characteristics (i.e., textural properties and surface

464 chemistry) also caused the different the $Q^{o}{ }_{\max }$ values.

465 Generally, in the same feedstock (i.e., golden shower pod as a typical example), the $S_{\text {BET }}$

466 values followed activated carbon $>$ biochar $>$ hydrochar $>$ biosorbent and the density of oxygen-

467 contain functionalities followed biosorbent $>$ hydrochar $>$ activated carbon $>$ biochar. In contrast,

468 the $Q_{\max }^{o}$ values exhibited the following order: activated carbon > biosorbent > hydrochar > 469 biochar. Therefore, to some extent, the density of oxygen-containing functionalities of an 470 adsorbent played a more critical role than its BET specific surface area. A comprehensive 471 comparison of the properties (i.e., textural, structural, morphological, physicochemical, crystal, 472 thermally stable properties, and surface chemistry) of activated carbons prepared from different 473 chemical activation methods and their precursors (i.e., biosorbent, hydrochar, and biochar) has 474 been reported in detail in our recent study (Tran et al., 2017e).

475 
479 The adsorption process was strongly dependent on the $\mathrm{pH}$ of the dye solution and the presence of 480 the electrolyte. The kinetic study confirmed that adsorption equilibrium was established rapidly 481 with low activation energies (from -48.6 to $-7.23 \mathrm{~kJ} / \mathrm{mol}$ ), and that, removal rates of $30 \%-87 \%$ 482 and 52\%-93\% can be achieved within 1 min and 5 min of contact, respectively. The maximum 483 monolayer adsorption capacities were ranked as follows: GS (106 mg/g) > OP (92 mg/g) $>$ CC (59 $484 \mathrm{mg} / \mathrm{g})$. The thermodynamic study suggested that the dye adsorption occurred spontaneously $\left(-\Delta G^{\circ}\right)$ 485 and exothermically $\left(-\Delta H^{\circ}\right)$. The primary adsorption mechanisms involved electrostatic interaction, 486 hydrogen bonding formations, and $n-\pi$ interaction. The carboxylic groups played a dominant role 487 in the adsorption process, and the three biopolymer components (i.e., hemicellulose, cellulose, and 488 lignin) contributed substantially. These three agricultural wastes could be low-cost, renewable 489 candidates for efficient dye adsorption.

\section{Acknowledgements}

492 This current work was financially supported by Chung Yuan Christian University (CYCU) in 493 Taiwan. The first author would like to thank CYCU for the Distinguished International Graduate 494 Students (DIGS) scholarship to pursue his doctoral studies. The authors gratefully acknowledge 495 the five anonymous reviewers for their invaluable insight and helpful suggestion to improve the 496 quality and acceptability of the paper.

\section{References}

Annadurai, G., R.-S. Juang and D.-J. Lee (2002). Use of cellulose-based wastes for adsorption of dyes from aqueous solutions. Journal of Hazardous Materials, 92(3), 263-274. 4905-4909. 
Blanchard, G., M. Maunaye and G. Martin (1984). Removal of heavy metals from waters by means of natural zeolites. Water Research, 18(12), 1501-1507.

Contreras, E., L. Sepúlveda and C. Palma (2012). Valorization of Agroindustrial Wastes as Biosorbent for the Removal of Textile Dyes from Aqueous Solutions. International Journal of Chemical Engineering, 2012, 9.

Ghaedi, M., H. Karimi and F. Yousefi (2014). Silver and zinc oxide nanostructures loaded on activated carbon as new adsorbents for removal of methylene green. Human \& Experimental Toxicology, 33(9), 956-967.

Giles, C. H., D. Smith and A. Huitson (1974). A general treatment and classification of the solute adsorption isotherm. I. Theoretical. Journal of Colloid and Interface Science, 47(3), 755765 .

Goertzen, S. L., K. D. Thériault, A. M. Oickle, A. C. Tarasuk and H. A. Andreas (2010). Standardization of the Boehm titration. Part I. $\mathrm{CO}_{2}$ expulsion and endpoint determination. Carbon, 48(4), 1252-1261.

Gupta, V. K. and Suhas (2009). Application of low-cost adsorbents for dye removal - A review. Journal of Environmental Management, 90(8), 2313-2342.

Hall, K. R., L. C. Eagleton, A. Acrivos and T. Vermeulen (1966). Pore- and Solid-Diffusion Kinetics in Fixed-Bed Adsorption under Constant-Pattern Conditions. Industrial \& Engineering Chemistry Fundamentals, 5(2), 212-223.

Hai, T. N. (2017). Comments on "Effect of Temperature on the Adsorption of Methylene Blue Dye onto Sulfuric Acid-Treated Orange Peel". Chemical Engineering Communications, 204(1),134-139.

Huang, F.-C., C.-K. Lee, Y.-L. Han, W.-C. Chao and H.-P. Chao (2014). Preparation of activated carbon using micro-nano carbon spheres through chemical activation. Journal of the Taiwan Institute of Chemical Engineers, 45(5), 2805-2812.

Jeyagowri, B. and R. T. Yamuna (2016). Potential efficacy of a mesoporous biosorbent Simarouba glauca seed shell powder for the removal of malachite green from aqueous solutions. Desalination and Water Treatment, 57(24), 11326-11336.

Köseoğlu, E. and C. Akmil-Başar (2015). Preparation, structural evaluation and adsorptive properties of activated carbon from agricultural waste biomass. Advanced Powder Technology, 26(3), 811-818.

Lagergren, S. (1898). About the theory of so-called adsorption of soluble substances. Kungliga Svenska Vetenskapsakademiens Handlingar, 24(4), 1-39. 
Lee, C.-K., S.-S. Liu, L.-C. Juang, C.-C. Wang, K.-S. Lin and M.-D. Lyu (2007). Application of MCM-41 for dyes removal from wastewater. Journal of Hazardous Materials, 147(3), 997-1005.

Lin, K.-S., H.-W. Cheng, W.-R. Chen and C.-F. Wu (2010). Synthesis, characterization, and adsorption kinetics of titania nanotubes for basic dye wastewater treatment. Adsorption, 16(1), 47-56.

Mattson, J. A., H. B. Mark, M. D. Malbin, W. J. Weber and J. C. Crittenden (1969). Surface chemistry of active carbon: Specific adsorption of phenols. Journal of Colloid and Interface Science, 31(1), 116-130.

Milonjić, S. K. (2009). Comments on "removal of uranium (VI) from aqueous solution by adsorption of hematite", by X. Shuibo, Z. Chun, Z. Xinghuo, Y. Jing, Z. Xiaojian, W. Jingsong. Journal of Environmental Radioactivity, 100(10), 921-922.

Mujtaba, M., I. Sargin and M. Kaya (2016). Determination of Bovine Serum Albumin Adsorption Capacity of Newly Obtained Cellulose extracted from Glycyrrhiza glabra (Licorice). Advances in Polymer Technology.

Ncibi, M. C., A. M. B. Hamissa, A. Fathallah, M. H. Kortas, T. Baklouti, B. Mahjoub and M. Seffen (2009). Biosorptive uptake of methylene blue using Mediterranean green alga Enteromorpha spp. Journal of Hazardous Materials, 170(2-3), 1050-1055.

Oladipo, A. A. and M. Gazi (2015). Two-stage batch sorber design and optimization of biosorption conditions by Taguchi methodology for the removal of acid red 25 onto magnetic biomass. Korean Journal of Chemical Engineering, 32(9), 1864-1878.

Raval, N. P., P. U. Shah and N. K. Shah (2016). Adsorptive amputation of hazardous azo dye Congo red from wastewater: a critical review. Environmental Science and Pollution Research, 23(15), 14810-14853.

Roginsky, S. and Y. B. Zeldovich (1934). The catalytic oxidation of carbon monoxide on manganese dioxide. Acta Phys. Chem. USSR, 1, 554.

Roosta, M., M. Ghaedi and F. Yousefi (2015). Optimization of the combined ultrasonic assisted/adsorption method for the removal of malachite green by zinc sulfide nanoparticles loaded on activated carbon: experimental design. RSC Advances, 5(121), 100129-100141.

Sadaf, S., H. N. Bhatti, S. Nausheen and M. Amin (2015). Application of a novel lignocellulosic biomaterial for the removal of Direct Yellow 50 dye from aqueous solution: Batch and column study. Journal of the Taiwan Institute of Chemical Engineers, 47, 160-170.

Shiau, C. Y. and C. C. Pan (2005). Adsorption of Basic Dyes from Aqueous Solution by Various Adsorbents. Separation Science and Technology, 39(8), 1733-1750. 
Tahir, N., H. N. Bhatti, M. Iqbal and S. Noreen (2017). Biopolymers composites with peanut hull waste biomass and application for Crystal Violet adsorption. International Journal of Biological Macromolecules, 94 Part A, 210-220.

Tran, H. N., F.-C. Huang, C.-K. Lee and H.-P. Chao (2017a). Activated carbon derived from spherical hydrochar functionalized with Triethylenetetramine: synthesis, characterizations, and adsorption application. Green Processing and Synthesis. DOI: 10.1515/gps-2016-0178.

Tran, H. N., Y.-F. Wang, S.-J. You and H.-P. Chao (2017b). Insights into the mechanism of cationic dye adsorption on activated charcoal: the importance of $\pi-\pi$ interactions. Process Safety and Environmental Protection, 17, 168-180.

Tran, H. N., Y.-F. Wang, S.-J. You and H.-P. Chao (2017c). Sustainable Biochar Derived from Agricultural Waste for Removal of Methylene Green 5 from Aqueous Solution: Adsorption Kinetic, Isotherm, Thermodynamic, and Mechanism Analysis.

Tran, H. N., S.-J. You, H.-B. Ahmad and H.-P. Chao (2017d). Mistakes and inconsistencies regarding adsorption of contaminants from aqueous solutions: A critical review. Water Research. DOI: DOI: 10.1016/j.watres.2017.04.014.

Tran, H. N., S.-J. You and H.-P. Chao (2016a). Effect of pyrolysis temperatures and times on the adsorption of cadmium onto orange peel derived biochar. Waste Management \& Research, 34(2), 129-138.

Tran, H. N., S.-J. You and H.-P. Chao (2016b). Thermodynamic parameters of cadmium adsorption onto orange peel calculated from various methods: A comparison study. Journal of Environmental Chemical Engineering, 4(3), 2671-2682.

Tran, H. N., S.-J. You and H.-P. Chao (2017e). Activated Carbons from Golden Shower upon Different Chemical Activation Methods: Synthesis and Characterizations. Adsorption Science \& Technology. DOI: 10.1177/0263617416684837.

Tran, H. N., S.-J. You and H.-P. Chao (2017f). Fast and efficient adsorption of methylene green 5 on activated carbon prepared from new chemical activation method. Journal of Environmental Management, 188, 322-336.

Tran, H. N., S.-J. You and H.-P. Chao (2017g). Insight into adsorption mechanism of cationic dye onto agricultural residues-derived hyrochars: negligible role of $\pi-\pi$ interaction. Korean Journal of Chemical Engineering. DOI: 10.1007/s11814-017-0056-7.

Wang, H., X. Yuan, Z. Wu, L. Wang, X. Peng, L. Leng and G. Zeng (2014). Removal of Basic Dye from Aqueous Solution using Cinnamomum camphora Sawdust: Kinetics, Isotherms, Thermodynamics, and Mass-Transfer Processes. Separation Science and Technology, 49(17), 2689-2699. 
607 Weber, W. J. and J. C. Morris (1963). Kinetics of adsorption on carbon from solution. Journal of 608 the Sanitary Engineering Division, 89(2), 31-60.

609 Witek-Krowiak, A. (2013). Biosorption of malachite green from aqueous solutions by pine 610

611 sawdust: equilibrium, kinetics and the effect of process parameters. Desalination and Water Treatment, 51(16-18), 3284-3294.

612 Xing, B., W. B. McGill, M. J. Dudas, Y. Maham and L. Hepler (1994). Sorption of phenol by 613

614 selected biopolymers: isotherms, energetics, and polarity. Environmental Science \& Technology, 28(3), 466-473.

615 Yang, H., R. Yan, H. Chen, D. H. Lee and C. Zheng (2007). Characteristics of hemicellulose, 616 cellulose and lignin pyrolysis. Fuel, 86(12-13), 1781-1788.

617

618 


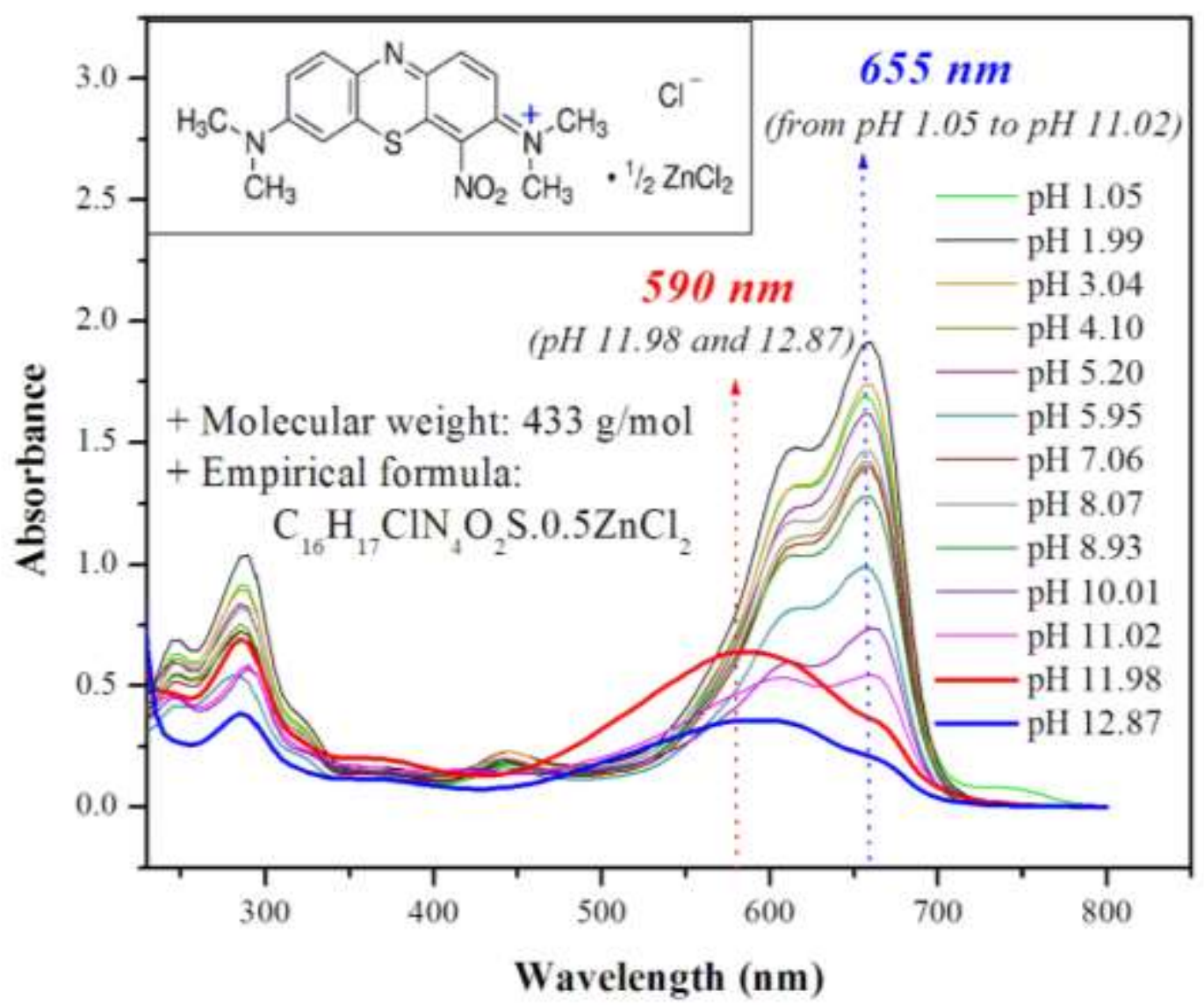

Figure 1. Effect of the $\mathrm{pH}$ of the MG5 solution on the $\lambda_{\max }$ value (Data published in our recent work; Tran et al., 2017f) 

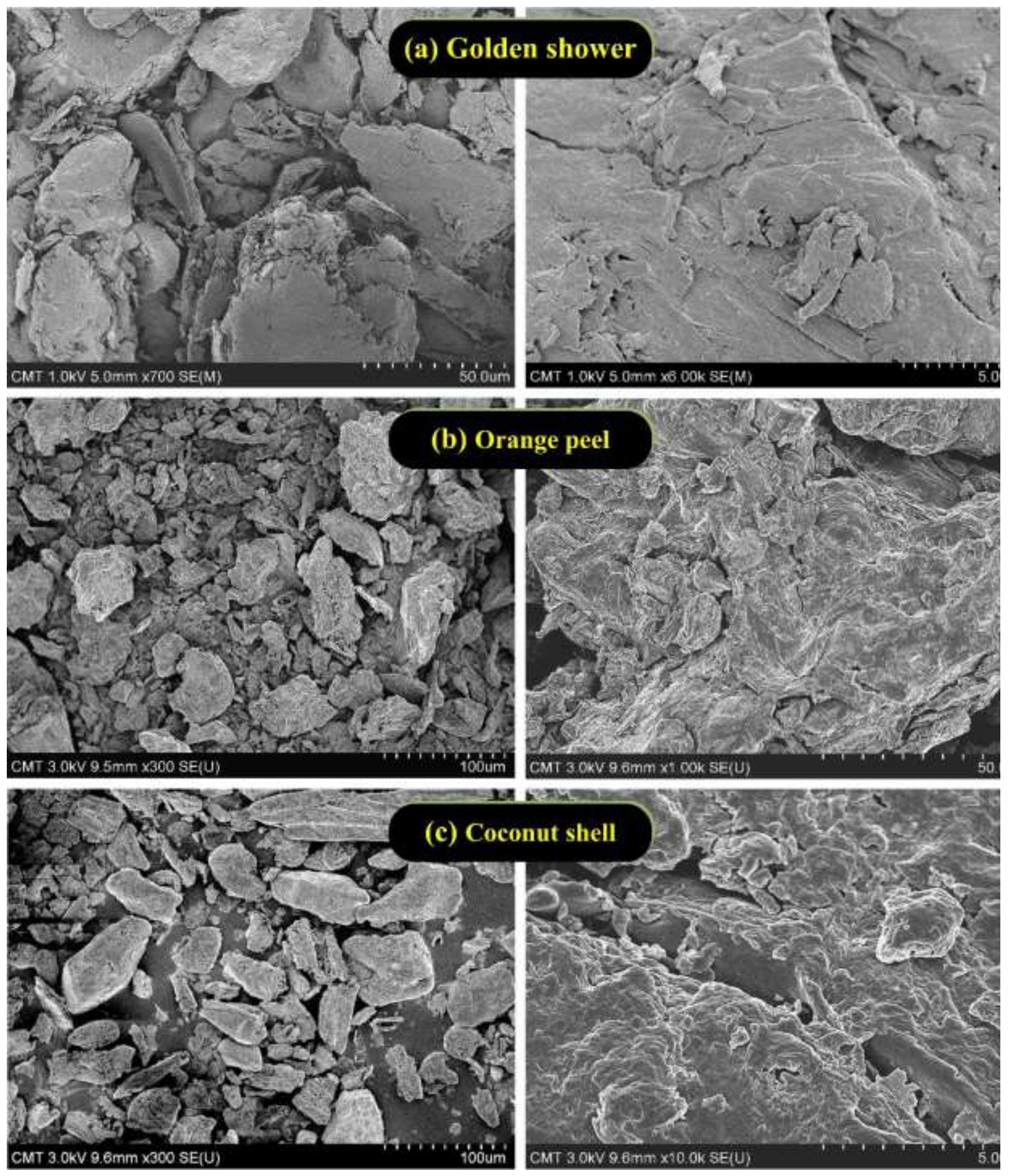


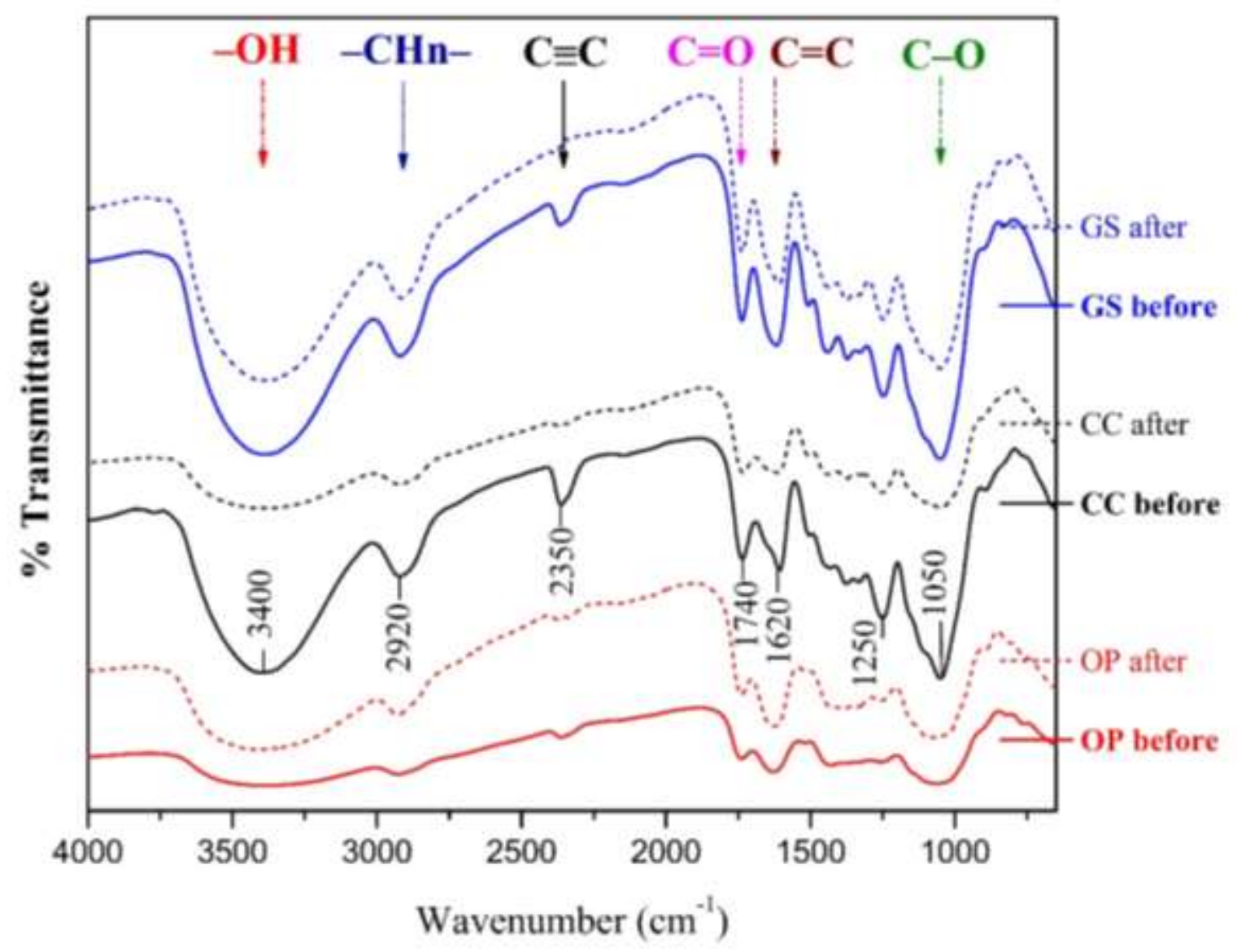

624

625 Figure 3. FT-IR spectra of the biosorbents before and after MG5 adsorption 626 (without baseline correction) 

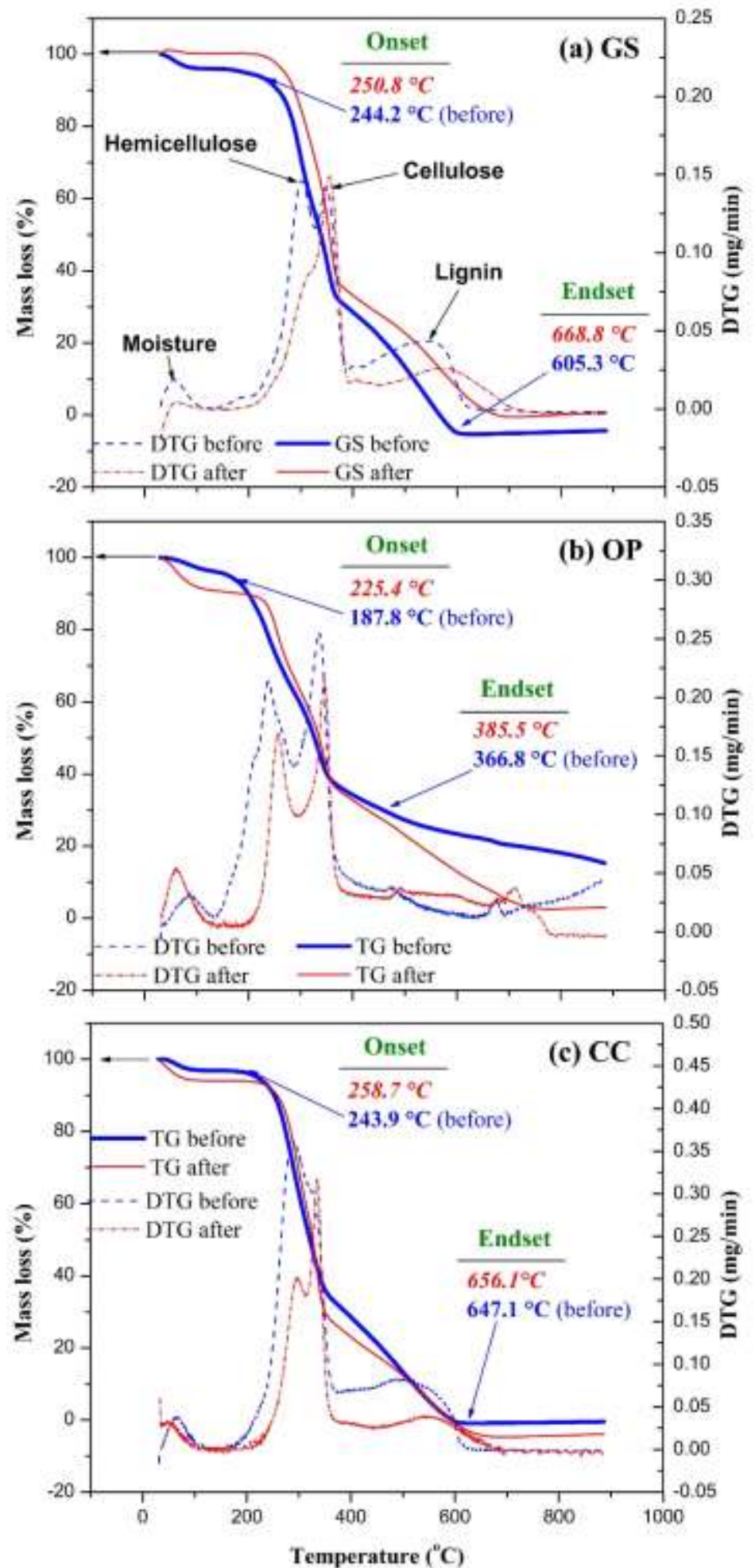

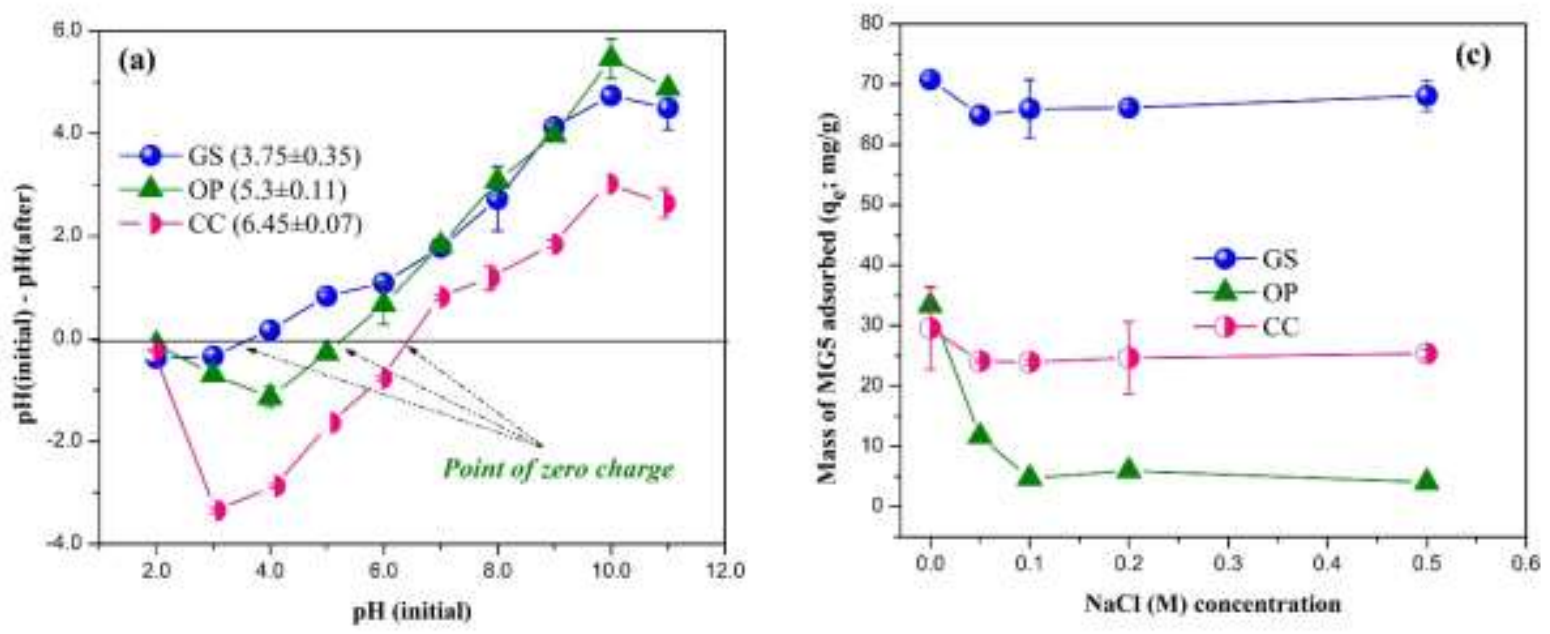

Initial solution $\mathrm{pH}$
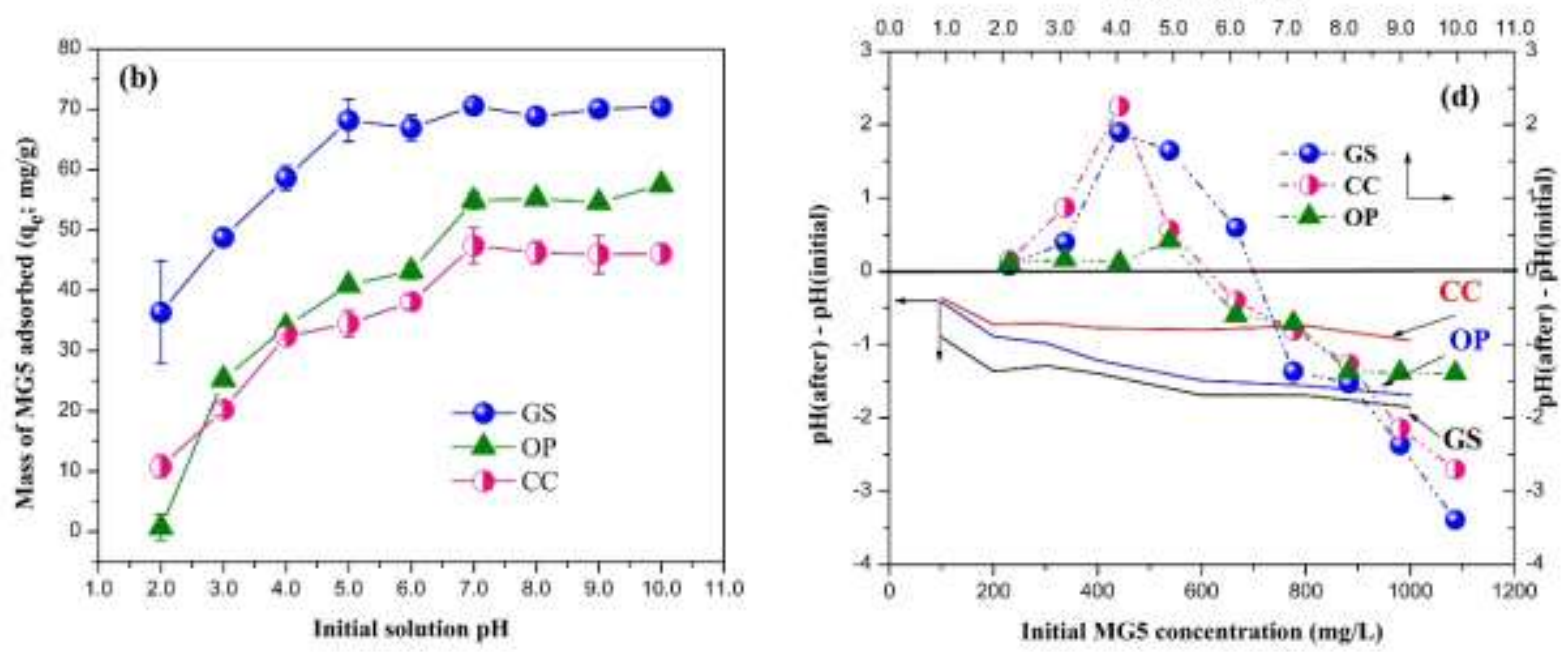

630

631 Figure 5. (a) The PZC values of the biosorbents, (b) the dependence of the 632 adsorption capacity on the $\mathrm{pH},(\mathrm{c})$ the effect of the ionic strength on the adsorption capacity, and (d) the $\mathrm{pH}$ values after adsorption

634 (Experimental conditions: $t=24 \mathrm{~h}, C_{0}=300 \mathrm{mg} / \mathrm{L}, m / V=4.0 \mathrm{~g} / \mathrm{L} ; 0 \mathrm{M} \mathrm{NaCl}$ for 635 the experiments of the dependence of the adsorption capacity on the $\mathrm{pH}$ and initial 636 solution $\mathrm{pH} 7.0$ for the experiments of the effect of the ionic strength). 

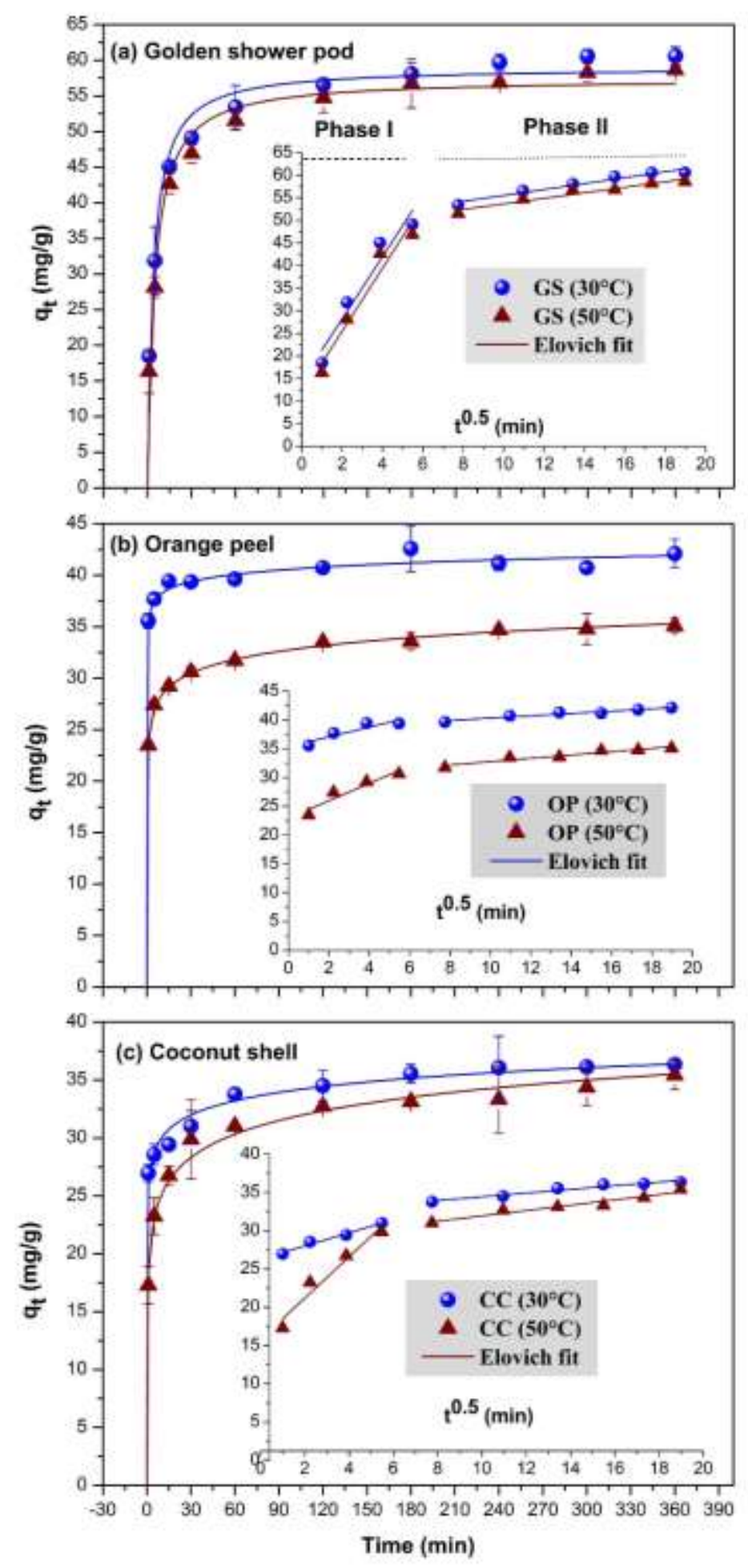

Figure 6. MG5 adsorption kinetics at different temperatures and intra-particle diffusion plots for MG5 adsorption (figures inside)

640 (Experimental conditions: $\mathrm{pH} 7.0,0 \mathrm{M} \mathrm{NaCl}, m / V=4.0 \mathrm{~g} / \mathrm{L}$, and $C_{0}=330 \mathrm{mg} / \mathrm{L}$ ) 

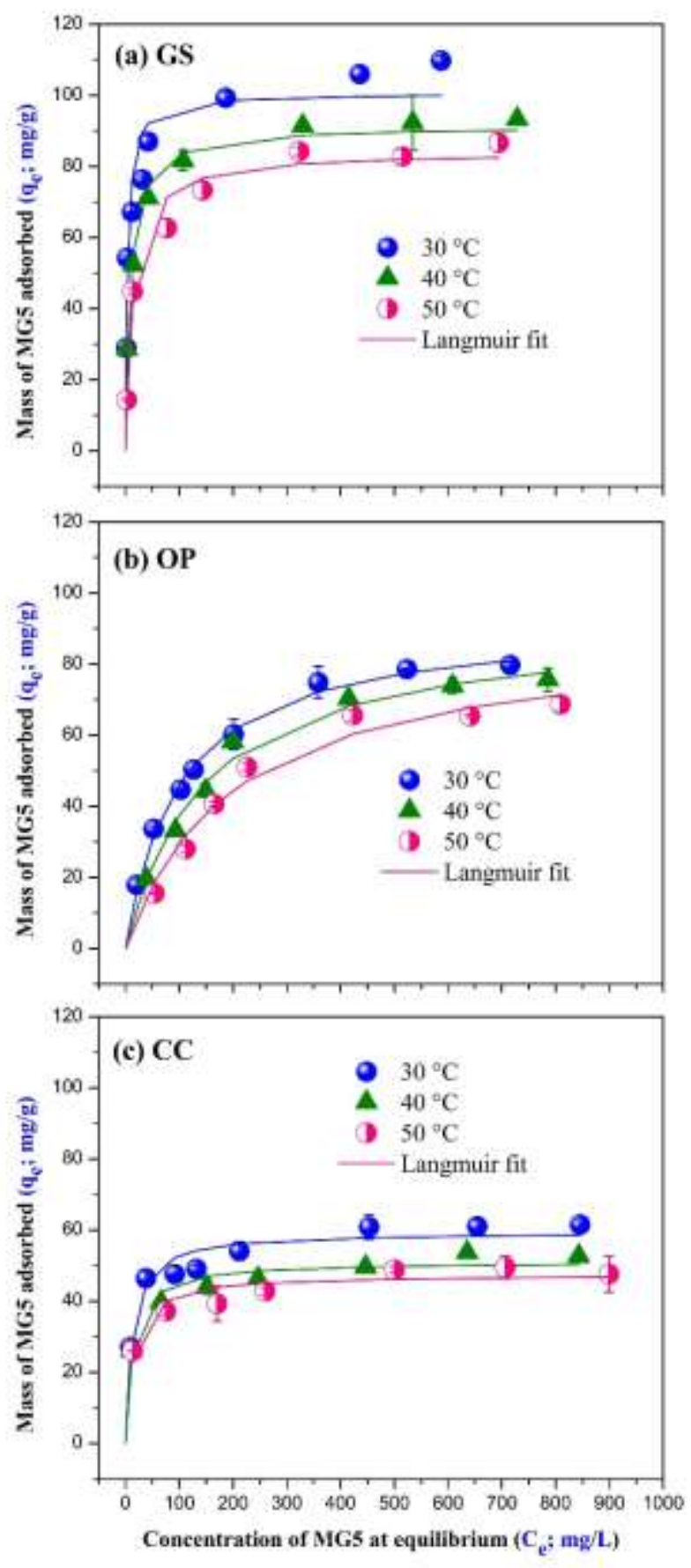
$100-1,000 \mathrm{mg} / \mathrm{L})$ 
645

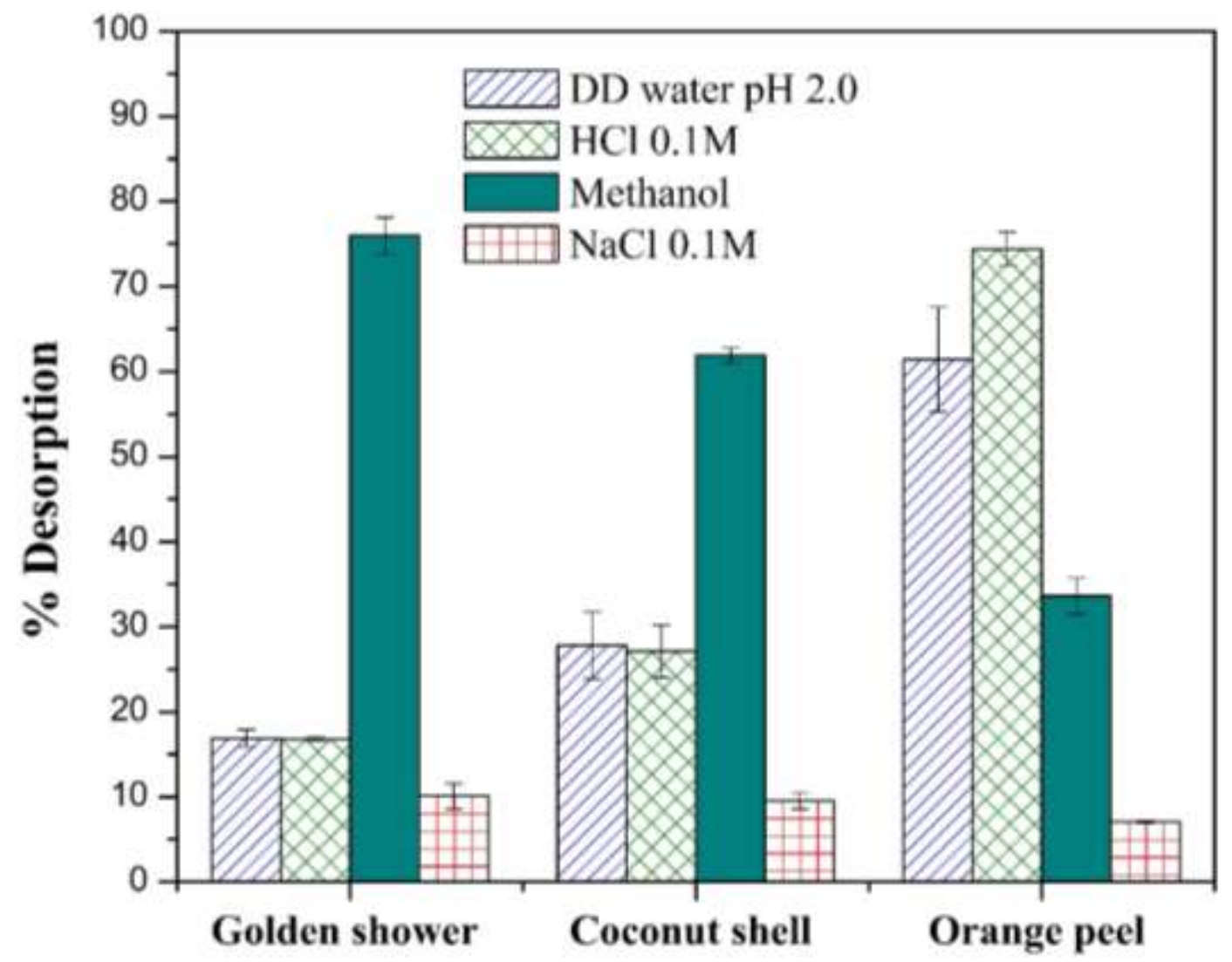

646

Figure 8. Percentage of MG5 desorbed using various desorbing agents

647 
(c) Yoshida H-bonding

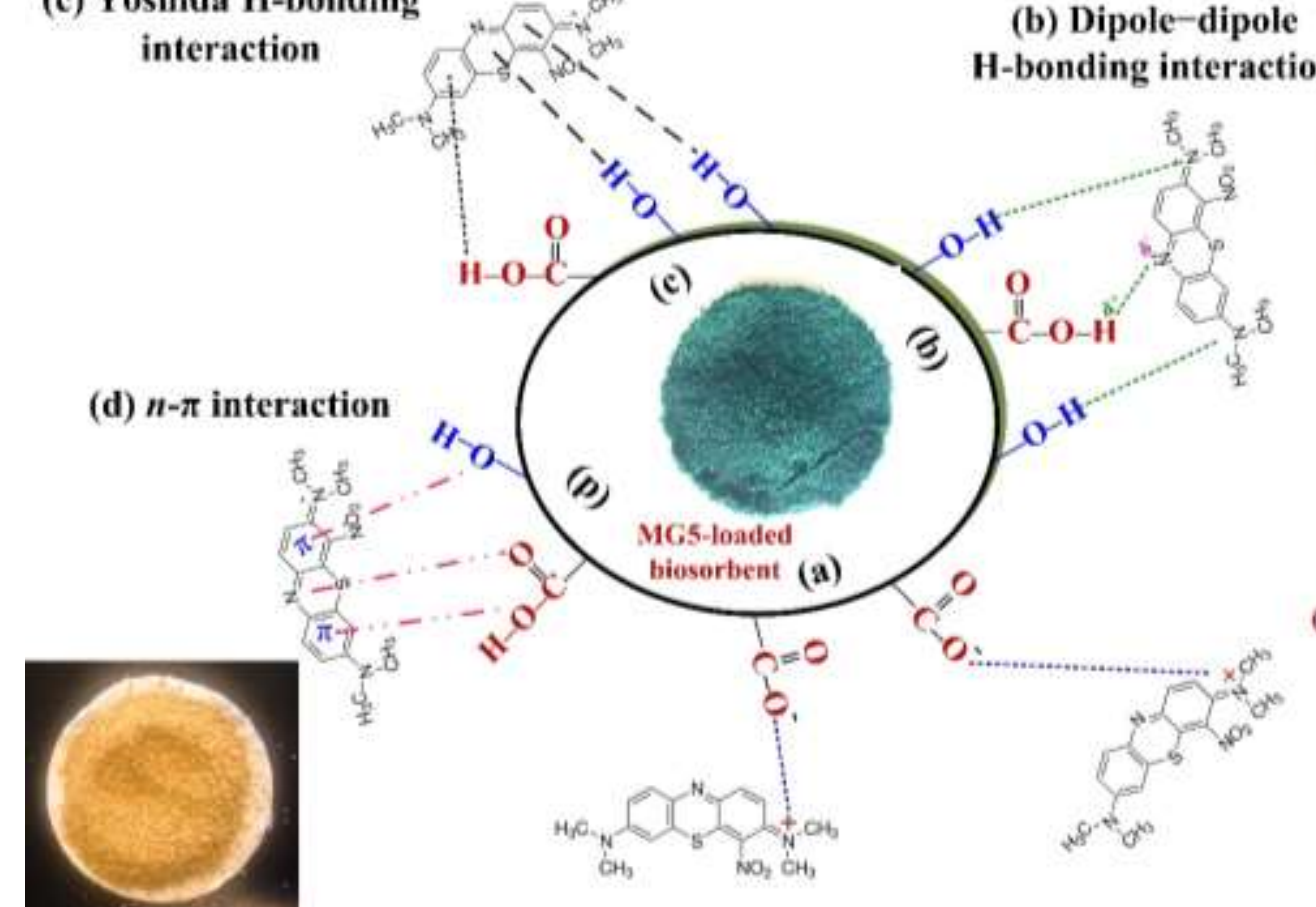

(a) Electrostatic interaction 
653 Table 1. Basic characteristics of the pristine biosorbent samples

\begin{tabular}{|c|c|c|c|c|}
\hline & Unit & GS & $\mathrm{CC}$ & OP \\
\hline \multicolumn{5}{|c|}{ 1. Textural properties } \\
\hline $\mathrm{S}_{\mathrm{BET}}$ & $\mathrm{m}^{2} / \mathrm{g}$ & 5.727 & 3.167 & 2.086 \\
\hline$S_{\text {Langmuir }}$ & $\mathrm{m}^{2} / \mathrm{g}$ & 16.78 & 8.093 & 7.185 \\
\hline$S_{\text {External }}$ & $\mathrm{m}^{2} / \mathrm{g}$ & 14.54 & 6.367 & 4.339 \\
\hline $\mathrm{V}_{\text {total }} \times 10^{-3}$ & $\mathrm{~cm}^{3} / \mathrm{g}$ & 9.962 & 4.135 & 4.237 \\
\hline \multicolumn{5}{|c|}{ 2. Physicochemical properties } \\
\hline Hardness & $\%$ & $49.1 \pm 2.01$ & $58.5 \pm 2.51$ & $39.7 \pm 1.15$ \\
\hline Bulk density & $\mathrm{g} / \mathrm{cm}^{3}$ & $0.66 \pm 0.02$ & $0.65 \pm 0.20$ & $0.61 \pm 0.05$ \\
\hline $\mathrm{pH}_{1: 20}$ & - & $5.43 \pm 0.33$ & $6.5 \pm 0.25$ & $4.69 \pm 0.18$ \\
\hline \multicolumn{5}{|l|}{ 3. Ultimate analysis } \\
\hline $\mathrm{C}$ & wt $\%$ & 53.39 & 55.50 & 54.34 \\
\hline $\mathrm{H}$ & $\mathrm{wt} \%$ & 6.14 & 6.273 & 5.91 \\
\hline $\mathrm{N}$ & $\mathrm{wt} \%$ & 0.84 & 0.44 & 1.14 \\
\hline $\mathrm{O}^{\mathrm{a}}$ & wt $\%$ & 39.63 & 37.79 & 38.61 \\
\hline \multicolumn{5}{|l|}{ 4. Proximate analysis } \\
\hline Moisture & wt $\%$ & $5.80 \pm 0.28$ & $8.09 \pm 1.59$ & $8.54 \pm 1.98$ \\
\hline Total ash & wt $\%$ & $1.17 \pm 0.30$ & $1.67 \pm 0.15$ & $3.49 \pm 0.99$ \\
\hline Volatile & wt $\%$ & $76.2 \pm 0.53$ & $73.0 \pm 3.34$ & $74.3 \pm 2.95$ \\
\hline Fixed carbon ${ }^{\mathrm{a}}$ & $\mathrm{wt} \%$ & $16.8 \pm 0.78$ & $17.2 \pm 1.91$ & $13.6 \pm 2.18$ \\
\hline \multicolumn{5}{|c|}{ 5. Boehm titration results } \\
\hline Total acidic groups & $\mathrm{mmol} / \mathrm{g}$ & $8.74 \pm 0.21$ & $4.21 \pm 0.25$ & $6.90 \pm 0.38$ \\
\hline + Phenolic & $\mathrm{mmol} / \mathrm{g}$ & $0.37 \pm 0.38$ & $2.15 \pm 0.95$ & $1.97 \pm 0.18$ \\
\hline + Lactonic & $\mathrm{mmol} / \mathrm{g}$ & $1.75 \pm 0.21$ & $0.96 \pm 0.15$ & $0.85 \pm 0.49$ \\
\hline + Carboxylic & $\mathrm{mmol} / \mathrm{g}$ & $6.16 \pm 0.14$ & $1.10 \pm 0.25$ & $4.07 \pm 0.66$ \\
\hline Total basic groups & $\mathrm{mmol} / \mathrm{g}$ & $0.12 \pm 0.30$ & $2.25 \pm 0.55$ & $2.14 \pm 0.63$ \\
\hline
\end{tabular}

657

658

659 
660 Table 2. FTIR spectral characteristics $\left(\mathrm{cm}^{-1}\right)$ of the biosorbents before and after MG5 adsorption 661

\begin{tabular}{lcccc}
\hline \multirow{2}{*}{ Samples } & \multicolumn{4}{c}{ Functional groups } \\
\cline { 2 - 5 } & $\mathrm{O}-\mathrm{H}$ & $\mathrm{C}=\mathrm{C}$ & $\mathrm{C}=\mathrm{O}$ & $\mathrm{C}-\mathrm{O}$ \\
\hline Pristine GS & 3389 & 1738 & 1678 & 1052 \\
MG5-loaded GS & 3390 & 1736 & 1608 & 1050 \\
Pristine CC & 3392 & 1734 & 1613 & 1050 \\
MG5-loaded CC & 3395 & 1737 & 1606 & 1050 \\
Pristine OP & 3393 & 1739 & 1630 & 1065 \\
MG5-loaded OP & 3397 & 1739 & 1625 & 1073 \\
\hline
\end{tabular}

662 
664 Table 3. $\mathrm{T}_{\max }$ values and mass loss percentages of the main components of the biosorbents before 665 and after the adsorption of MG5

\begin{tabular}{|c|c|c|c|c|c|c|c|}
\hline \multirow{3}{*}{$\begin{array}{l}\text { DTG } \\
\text { peak }\end{array}$} & \multicolumn{6}{|c|}{$\mathrm{T}_{\max }\left({ }^{\circ} \mathrm{C}\right) / \mathrm{mass} \operatorname{loss}(\%)$} & \multirow{3}{*}{ Definition } \\
\hline & \multicolumn{3}{|c|}{ Before MG5 adsorption } & \multicolumn{3}{|c|}{ After MG5 adsorption } & \\
\hline & GS & $\mathrm{CC}$ & OP & GS & $\mathrm{CC}$ & OP & \\
\hline 1 & $54 / 1.39$ & $61 / 1.02$ & $87 / 2.01$ & $57 / 0.21$ & $53 / 3.06$ & $61 / 3.66$ & Moisture \\
\hline 2 & $299 / 26.8$ & $289 / 28.7$ & $237 / 19.5$ & $320 / 25.8$ & $299 / 27.0$ & $256 / 17.8$ & Hemicellulose \\
\hline 3 & $351 / 30.1$ & $327 / 23.5$ & $333 / 32.4$ & $356 / 26.0$ & $335 / 28.2$ & $346 / 34.6$ & Cellulose \\
\hline 4 & - & - & $490 / 18.1$ & - & - & $492 / 20.1$ & $\mathrm{CaO}$ \\
\hline 5 & $548 / 37.9$ & $498 / 33.2$ & $700 / 27.9$ & $583 / 37.8$ & $540 / 34.7$ & $711 / 23.4$ & Lignin \\
\hline
\end{tabular}


667 Table 4. Corresponding adsorption kinetic parameters for MG5 adsorption by GS, CC, and OP

\begin{tabular}{|c|c|c|c|c|c|c|}
\hline & \multicolumn{2}{|c|}{ GS } & \multicolumn{2}{|c|}{$\mathbf{O P}$} & \multicolumn{2}{|c|}{$\mathrm{CC}$} \\
\hline & $30{ }^{\circ} \mathrm{C}$ & $50{ }^{\circ} \mathrm{C}$ & $30^{\circ} \mathrm{C}$ & $50{ }^{\circ} \mathrm{C}$ & $30^{\circ} \mathrm{C}$ & $50{ }^{\circ} \mathrm{C}$ \\
\hline $\mathrm{q}_{\mathrm{e}, \exp }$ & 60.30 & 56.89 & 41.58 & 34.54 & 35.03 & 32.07 \\
\hline \multicolumn{7}{|c|}{ Pseudo-first-order model } \\
\hline $\mathrm{q}_{\mathrm{e}, \mathrm{cal}}$ & 59.39 & 54.76 & 40.30 & 32.32 & 33.49 & 31.45 \\
\hline $\mathrm{k}_{1}$ & 0.162 & 0.131 & 2.822 & 1.283 & 1.632 & 0.612 \\
\hline $\mathrm{R}^{2}$ & 0.844 & 0.874 & 0.540 & 0.488 & 0.258 & 0.577 \\
\hline$\chi^{2}$ & 30.81 & 25.94 & 5.105 & 7.336 & 9.247 & 13.85 \\
\hline \multicolumn{7}{|c|}{ Pseudo-second-order model } \\
\hline $\mathrm{q}_{\mathrm{e}, \mathrm{cal}}$ & 59.02 & 57.45 & 40.69 & 33.03 & 34.08 & 32.72 \\
\hline $\mathrm{k}_{2}\left(\times 10^{-3}\right)$ & 4.412 & 3.695 & 151.7 & 60.66 & 85.64 & 23.66 \\
\hline $\mathrm{R}^{2}$ & 0.953 & 0.963 & 0.653 & 0.716 & 0.475 & 0.833 \\
\hline$\chi^{2}$ & 9.165 & 7.640 & 1.514 & 4.062 & 6.551 & 5.468 \\
\hline \multicolumn{7}{|c|}{ Elovich model } \\
\hline$\alpha\left(\times 10^{3}\right)$ & 0.154 & 0.100 & 2108 & 456.6 & 4.065 & 1.682 \\
\hline$\beta$ & 0.141 & 0.138 & 0.982 & 0.518 & 0.564 & 0.345 \\
\hline $\mathrm{R}^{2}$ & 0.961 & 0.957 & 0.967 & 0.994 & 0.955 & 0.976 \\
\hline$\chi^{2}$ & 7.723 & 8.681 & 0.133 & 0.089 & 0.556 & 0.776 \\
\hline \multicolumn{7}{|c|}{ Intra-particle diffusion model } \\
\hline $\mathrm{K}_{\mathrm{ip}}$ & 1.863 & 1.897 & 0.285 & 0.536 & 0.519 & 0.779 \\
\hline $\mathrm{C}$ & 31.39 & 28.79 & 37.14 & 26.25 & 27.84 & 22.19 \\
\hline $\mathrm{R}^{2}$ & 0.741 & 0.739 & 0.833 & 0.847 & 0.911 & 0.784 \\
\hline$\chi^{2}$ & 11.85 & 13.07 & 0.161 & 0.687 & 0.307 & 2.508 \\
\hline \multicolumn{7}{|c|}{ Activation energy } \\
\hline $\mathrm{Ea}\left(\mathrm{k}_{1}\right)$ & \multicolumn{2}{|c|}{-8.64} & \multicolumn{2}{|c|}{-32.07} & \multicolumn{2}{|c|}{-39.90} \\
\hline $\mathrm{Ea}\left(\mathrm{k}_{2}\right)$ & \multicolumn{2}{|c|}{-7.22} & \multicolumn{2}{|c|}{-37.29} & \multicolumn{2}{|c|}{-52.33} \\
\hline $\operatorname{Ea}(\alpha)$ & \multicolumn{2}{|c|}{-17.45} & \multicolumn{2}{|c|}{-62.23} & \multicolumn{2}{|c|}{-35.23} \\
\hline $\mathrm{Ea}\left(\mathrm{k}_{\mathrm{ip}}\right)$ & \multicolumn{2}{|c|}{-3.52} & \multicolumn{2}{|c|}{-14.12} & \multicolumn{2}{|c|}{-9.23} \\
\hline
\end{tabular}

668 Note: the units of kinetic parameters are $q_{e}(\mathrm{mg} / \mathrm{g}), \beta(\mathrm{mg} / \mathrm{g}), k_{1}(1 / \mathrm{min}), k_{2}(\mathrm{~g} / \mathrm{mg} \times \mathrm{min}), k_{i p}$ 669 (mg/g $\times$ min), $\alpha(\mathrm{g} / \mathrm{mg} \times \mathrm{min}), \mathrm{Ea}(\mathrm{kJ} / \mathrm{mol})$. The kinetic parameters were determined by non-linear 670 method, expected for the intra-particle diffusion model.

671 
672 Table 5. Relative adsorption isotherm parameters for MG5 adsorption

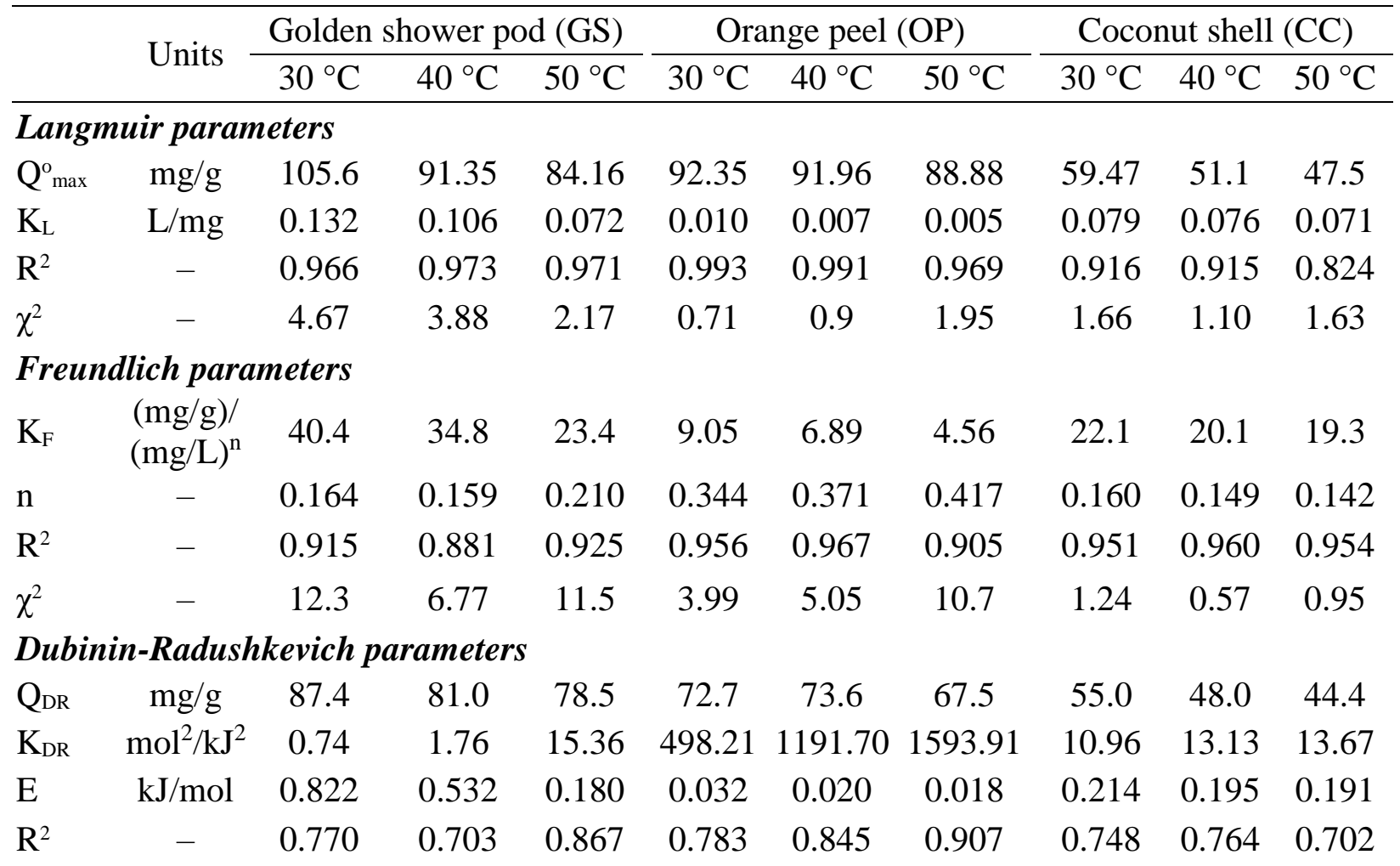

Separation factor

$\mathrm{R}_{\mathrm{L}} \quad \times 10^{-3} \quad 7.2-60.3 \quad 8.6-74.1 \quad 13-126 \quad 88-508$ 116-550 155-629 11.4-97 12-101 13-106

673 Note: the parameters from the selected models were determined using non-linear method. 
674 Table 6. Adsorption thermodynamics parameters for MG5 adsorption

\begin{tabular}{|c|c|c|c|c|c|}
\hline $\begin{array}{c}\mathrm{T} \\
(\mathrm{K})\end{array}$ & $\begin{array}{l}\text { van't Hoff } \\
\text { equation }\end{array}$ & $\mathrm{K}_{\mathrm{C}}$ & $\begin{array}{c}\Delta \mathrm{G}^{\mathrm{o}} \\
(\mathrm{kJ} / \mathrm{mol})\end{array}$ & $\begin{array}{c}\Delta \mathrm{H}^{\mathrm{o}} \\
(\mathrm{kJ} / \mathrm{mol})\end{array}$ & $\begin{array}{c}\Delta \mathrm{S}^{\mathrm{o}} \\
(\mathrm{J} / \mathrm{mol} \times \mathrm{K})\end{array}$ \\
\hline \multicolumn{6}{|c|}{ Golden shower pod (GS) } \\
\hline 303 & $v=2056 x+207$ & 131900 & -29.72 & \multirow[t]{3}{*}{-24.57} & \multirow[t]{3}{*}{17.21} \\
\hline 313 & $\begin{array}{l}y=2956 x+2.07 \\
D 2-0.060\end{array}$ & 105900 & -30.12 & & \\
\hline 323 & & 72000 & -30.05 & & \\
\hline \multicolumn{6}{|c|}{ Orange peel (OP) } \\
\hline 303 & $2407 \mathrm{x} 202$ & 10022 & -23.22 & \multirow{3}{*}{-28.33} & \multirow[t]{3}{*}{-18.32} \\
\hline 313 & $\begin{array}{l}y=340 / x-2.03 \\
R^{2}-0.099\end{array}$ & 6933 & -23.03 & & \\
\hline 323 & & 5000 & -22.88 & & \\
\hline \multicolumn{6}{|c|}{ Coconut shell (CC) } \\
\hline 303 & $y-400 y+063$ & 79100 & -28.43 & \multirow[t]{3}{*}{-4.151} & \multirow[t]{3}{*}{80.10} \\
\hline 313 & $\begin{array}{l}y=499 x+9.63 \\
P^{2}-0.091\end{array}$ & 75652 & -29.25 & & \\
\hline 323 & $\mathrm{~K}^{2}=0.991$ & 71423 & -30.03 & & \\
\hline
\end{tabular}

675

676

677

678 
679 Table 7. Comparison of the cationic dye maximum capacities $\left(Q^{o} \max \right)$ of the biosorbents studied 680 here and those of other biosorbents reported in the literature

\begin{tabular}{|c|c|c|c|c|}
\hline Biosorbent & Dye & $\begin{array}{c}\text { Mw } \\
(\mathrm{g} / \mathrm{mol})\end{array}$ & $\begin{array}{c}\mathbf{Q}^{\mathbf{o}} \max \\
(\mathrm{mmol} / \mathrm{g})\end{array}$ & Reference \\
\hline \multirow{2}{*}{ Cinnamomum camphora } & & 365 & & \\
\hline & MG & & 0.424 & Wang et al. (2014) \\
\hline \multirow[t]{2}{*}{ Simarouba glauca } & & 365 & & \\
\hline & $M G$ & & 0.342 & Jeyagowri and Yamuna (2016) \\
\hline Orange peel & BB41 & 483 & 0.326 & Contreras et al. (2012) \\
\hline Chitosan aniline composite with PH & $\mathrm{CV}$ & 408 & 0.257 & Tahir et al. (2017) \\
\hline Starch composite with $\mathrm{PH}$ & $\mathrm{CV}$ & 408 & 0.248 & Tahir et al. (2017) \\
\hline Golden shower & MG & 433 & 0.244 & This study \\
\hline Chitosan pyrrole composite with $\mathrm{PH}$ & $\mathrm{CV}$ & 408 & 0.229 & Tahir et al. (2017) \\
\hline Polyaniline composite with PH & $\mathrm{CV}$ & 408 & 0.221 & Tahir et al. (2017) \\
\hline Polypyrrole composite with PH & $\mathrm{CV}$ & 408 & 0.218 & Tahir et al. (2017) \\
\hline Orange peel & MG5 & 433 & 0.213 & This study \\
\hline Pine sawdust & MG & 365 & 0.196 & Witek-Krowiak (2013) \\
\hline Coconut shell & MG5 & 433 & 0.137 & This study \\
\hline Brewer's spent grains & BB41 & 483 & 0.067 & Contreras et al. (2012) \\
\hline Banana peel & D & ברב & & Annadurai et al. (2002) \\
\hline Orange peel & MB & 320 & 0.058 & Annadurai et al. (2002) \\
\hline \multirow{2}{*}{$\begin{array}{l}\text { Banana peel } \\
\text { Orange peel }\end{array}$} & MV & 256 & 0.048 & \multirow{2}{*}{$\begin{array}{l}\text { Annadurai et al. (2002) } \\
\text { Annadurai et al. (2002) }\end{array}$} \\
\hline & MV & 256 & 0.045 & \\
\hline \multirow{2}{*}{$\begin{array}{l}\text { Banana peel } \\
\text { Orange peel }\end{array}$} & $\mathrm{RB}$ & 479 & 0.043 & \multirow{2}{*}{$\begin{array}{l}\text { Annadurai et al. (2002) } \\
\text { Annadurai et al. (2002) }\end{array}$} \\
\hline & $\mathrm{RB}$ & 479 & 0.030 & \\
\hline
\end{tabular}


681 Note: $M G 5$ (methylene green 5); MG (Malachite green); MB (Methylene blue); MV (Methyl violet); RB 682 (Rhodamine B); BB41 (Basic Blue 41); CV (Crystal Violet); and PH (peanut hull)

683

684 
685 Table 8. Comparison of the maximum capacities $\left(Q^{o} \max \right)$ of MG5 adsorption by the biosorbents 686 studied here and those of other adsorbents reported in the literature

\begin{tabular}{|c|c|c|c|c|c|}
\hline Adsorbent & $\begin{array}{c}\mathbf{S}_{\text {BET }} \\
\left(\mathrm{m}^{2} / \mathbf{g}\right)\end{array}$ & pH & $\begin{array}{c}\mathbf{T} \\
\left({ }^{\circ} \mathbf{C}\right) \\
\end{array}$ & $\begin{array}{c}Q^{\mathbf{o}}{ }_{\text {max }} \\
(\mathrm{mg} / \mathrm{g})\end{array}$ & Reference \\
\hline \multicolumn{6}{|l|}{ Biosorbent } \\
\hline Golden shower & 5.727 & 7.0 & 30 & 106 & This study \\
\hline Coconut shell & 3.167 & 7.0 & 30 & 59.5 & This study \\
\hline Orange peel & 2.086 & 7.0 & 30 & 92.4 & This study \\
\hline \multicolumn{6}{|l|}{ Hydrochar } \\
\hline Golden shower & 14.7 & 7.0 & 30 & 59.6 & Tran et al. $(2017 \mathrm{~g})$ \\
\hline Coconut shell & 6.65 & 7.0 & 30 & 32.7 & Tran et al. $(2017 \mathrm{~g})$ \\
\hline Orange peel & 6.99 & 7.0 & 30 & 15.6 & Tran et al. $(2017 \mathrm{~g})$ \\
\hline Commercial glucose & 7.08 & 5.0 & 25 & 13.9 & Tran et al. 2017a) \\
\hline \multicolumn{6}{|l|}{ Biochar } \\
\hline Golden shower & 604 & 7.0 & 30 & 45.5 & Tran et al. (2017c) \\
\hline Coconut shell & 536 & 7.0 & 30 & 41.5 & Tran et al. (2017c) \\
\hline Orange peel & 565 & 7.0 & 30 & 35.2 & Tran et al. (2017c) \\
\hline \multicolumn{6}{|l|}{ Activated carbon } \\
\hline Golden shower & $812-1,413$ & 7.0 & 30 & $253-531$ & Tran et al. (2017f) \\
\hline Orange peel & 1,025 & 7.0 & 30 & 330 & Tran et al. (2017f) \\
\hline Commercial glucose & 335 & 5.0 & 25 & 175 & Tran et al. (2017a) \\
\hline Commercial AC & 768 & 5.0 & 25 & 178 & Huang et al. (2014) \\
\hline Commercial xylose & 1,386 & 5.0 & 25 & 417 & Huang et al. (2014) \\
\hline Commercial sucrose & 1,494 & 5.0 & 25 & 299 & Huang et al. (2014) \\
\hline Commercial glucose & 1,612 & 5.0 & 25 & 444 & Huang et al. (2014) \\
\hline Norit RB4C & 1,026 & 7.0 & 30 & 543 & Tran et al. (2017b) \\
\hline Activated carbon & 946 & 3.0 & 25 & 272 & Shiau and Pan (2005) \\
\hline \multicolumn{6}{|l|}{ Others } \\
\hline Ag-NP-AC & NA & 7.0 & 25 & 167 & Ghaedi et al. (2014) \\
\hline ZnONR-AC & NA & 7.0 & 25 & 200 & Ghaedi et al. 2014) \\
\hline MCM-41 & 1,004 & 4.0 & 25 & 137 & Lee et al. (2007) \\
\hline GH-TETA $_{1 \%}$ & NA & 5.0 & 25 & 67.6 & Tran, et al. (2017a) \\
\hline $\mathrm{GAC}_{1 \%}$ & 233 & 5.0 & 25 & 101 & Tran, et al. (2017a) \\
\hline Montmorillonite & 165 & 3.0 & 25 & 128 & Shiau and Pan (2005) \\
\hline Activated clay & 278 & 3.0 & 25 & 271 & Shiau and Pan (2005) \\
\hline Titania nanotube & 292 & 4.0 & 25 & 292 & Lin et al. (2010) \\
\hline
\end{tabular}

